\title{
Inter- and Transdisciplinarity in Bioeconomy
}

\author{
Andrea Knierim, Lutz Laschewski, and Olga Boyarintseva
}

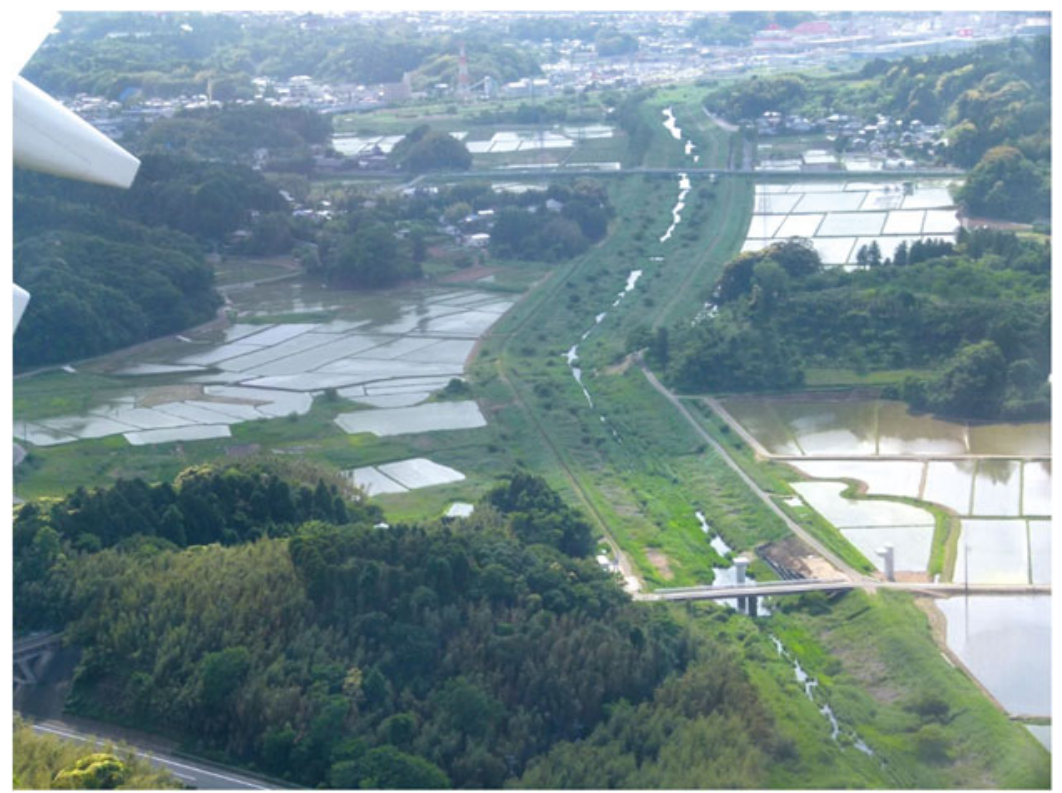

(C) Iris Lewandowski

\begin{abstract}
In this chapter, characteristics and definitions of inter- and transdisciplinary research are presented and discussed with specific attention to bioeconomyrelated policy discourses, concepts and production examples. Inter- and transdisciplinary research approaches have the potential to positively contribute to solving complex societal problems and to advance the generation
\end{abstract}

A. Knierim $(\bowtie) \cdot$ O. Boyarintseva Institute of Social Sciences in Agriculture, Rural Sociology, University of Hohenheim, Stuttgart, Germany e-mail: andrea.knierim@uni-hohenheim.de; allora26@gmail.com
L. Laschewski

Institute for Rural Studies, Johann Heinrich von Thünen Institute, Braunschweig, Germany e-mail: lutz.laschewski@thuenen.de 
of knowledge relevant for innovative solutions. As a key concept for integrating different disciplines across social and natural sciences within a common research project, we present principles, models and examples of system research and highlight systems practice with the help of the farming systems and the socioecological systems approaches. Next, we concretise inter- and transdisciplinary research practice as a three-phase process and operationalise cooperation of scientists and stakeholders in bioeconomy contexts. Specific attention is given to a differentiated understanding of knowledge. The chapter is closed with a reflection on the role researchers play in inter- and transdisciplinary research and the impacts created by norms and values emanating from science.

\section{Keywords}

Inter- and transdisciplinarity - Wicked problems - Types of knowledge • Systems thinking $\bullet$ Socioecological systems $\bullet$ Bioeconomy research

\section{Learning Objectives}

In this chapter, you will:

- Learn how inter- and transdisciplinary approaches contribute to knowledge generation in bioeconomy-related research.

- Understand system concepts' potential to integrate distinct disciplinary views in joint research.

- Reflect upon researchers' roles and tasks when interacting with others societal actor groups in common projects.

\subsection{Introduction: Why Inter- and Transdisciplinarity in Bioeconomy?}

In the first section of this chapter, we present our understanding of 'bioeconomy' as a political and societal discourse, as a concept constructed in complex interactions of public and private actors from both economy and civil society spheres within regions, nations and in international contexts. It is with this understanding in mind that we then argue for inter- and transdisciplinary research approaches.

\subsubsection{Bioeconomy as a Political Strategy for Sustainable Growth}

Following the early interpretations of 'bioeconomics' of Zeman and GeorgescuRoegen in the 1970s of the last century, the term was meant to designate 'a new economic order' which appropriately acknowledges the biological bases of (almost) any economic activities (Bonaiuti 2015). Apparently, the intention was not to encourage economic development and growth but to warn of the ecological and the sociocultural damages induced and to replace the prevailing economic model. Since then, the term 'bioeconomy' has become prominent in politics, science and economy (cf. Chap. 3), and it is a certain 'irony of fate' that Western nations make use of the 'bioeconomy concept' to promote and foster research and innovation processes with the aim to establish a better 'biobased' economic development and growth (e.g. BMBF 2010; OECD 2009; Staffas et al. 2013).

As a prominent example, the European Commission portrays the bioeconomy as a key component for smart and green growth. Utilising the results of the public consultation, the EC published a combined strategy and action plan document in 2012 entitled 'Innovating for Sustainable Growth: A Bioeconomy for Europe'. In 
this paper, bioeconomy is described as relying on 'the production of renewable biological resources and their conversion into food, feed, bio-based products and bioenergy', and comprising a broad array of economic sectors and branches, such as 'agriculture, forestry, fisheries, food and pulp and paper production, and parts of chemical, biotechnological and energy industries' (European Commission 2012, p. 5). The report states further the economic importance of the bioeconomy in terms of annual turnover and employment creation and also emphasises the strategical importance of the sector for the future of the European Union. More concretely, the strategy aims to improve the knowledge base for the bioeconomy, encourage innovation to increase natural resource productivity in a sustainable manner and assist the development of production systems that mitigate and adapt to the impacts of climate change. Importantly, the policy document calls for a strategic, comprehensive and coherent approach to deal with the complex and interdependent challenges related to the bioeconomy in Europe, such as competition between different biomass uses and potential impact on food prices. 'The Bioeconomy Strategy focuses on three large areas:

- The investment in research, innovation, and skills

- The reinforcement of policy interaction and stakeholder engagement

- The enhancement of markets and competitiveness in bioeconomy sectors' (European Commission 2012, p. 12).

In a similar way, the German national bioeconomy strategy emphasises the use of biomass for multiple purposes and also stresses the waste recycling as a major strategic field (BMEL 2014). More generally, the strategy highlights the objectives both to meet societal challenges such as world population growth, climate change and the loss of soil fertility and biodiversity as well as transforming the economy from a dependence on fossil resources towards a 'circular' or 'recycling' economy. Cross-cutting and thematic policy areas are thus interwoven (Table 4.1).

Political bioeconomy strategies have thus a strong focus on scientific development and equally underline the necessity of stakeholder integration and engagement. However, underlying innovation models seems to frequently be rather traditional models of exogenous innovation development with a strong focus on diffusion of innovation. Explicitly, this is visible in a chapter title 'Advancing from Lab to the Market' of the White House Bioeconomy Blueprint (2012). The innovation concept is presented with more details in Chap. 11.

Within a social sciences' perspective, bioeconomy can be understood as a policy discourse (see excursus box) that selects and defines societal problems (problem framing) and creates a 'performative narrative', i.e. a convincing story that offers solutions in this respect. The bioeconomy discourse combines various (environmental, economic and social) problem streams. With regard to environmental issues, it particularly addresses climate change and the limited availability of non-renewable (fossil) resources. These issues are connected with the socioeconomic challenge of growing demand for resources due to the global population growth and increasing incomes. In combination, these processes require a change of the economy (towards a bio-based economy) and growing productivity at the same time.

Table 4.1 Cross-cutting and thematic policy areas

$\begin{array}{ll}\text { Cross-cutting policy area } & \text { Thematic policy area } \\ \begin{array}{l}\text { Coherent policy } \\ \text { Information and public dialog }\end{array} & \begin{array}{l}\text { Sustainable production of renewable resources } \\ \text { Primary and vocational education }\end{array} \\ & \begin{array}{l}\text { Growing markets and innovation } \\ \text { Competition of land uses }\end{array} \\ & \text { International context }\end{array}$




\section{Box 4.1 Discourses}

'Discourse' has originally been used as a concept for sequential analysis of the flow of conversations. Then, the concept has become a much broader interpretation by the work of Michel Foucault (a French philosopher, 1926-1984), who defined discourse as 'systems of thoughts composed of ideas, attitudes, courses of action, beliefs and practices that systematically construct the subjects and the worlds of which they speak'. Foucault traced the role of discourses in wider social processes of legitimisation and power, emphasising the construction of current truths, how they are maintained and what power relations they carry with them. Foucault argued that discourse is a medium through which power relations produce speaking subjects and a practice through which power structures are reproduced. Thus, power and knowledge are interrelated, and therefore every human relationship is a struggle and negotiation of power.

Foucault's analysis has inspired discourse analysis in many fields, and it has become an integral part of political analysis in particular through the work of Maarten Hajer (a Dutch political scientist). He defined a policy discourse as ensemble of ideas, concepts and categories through which meaning is given to social and physical phenomena. It is produced and reproduced through an identifiable set of practices. In a policy arena, different, competing policy discourses may be identified. A policy discourse is produced and maintained by a discourse coalition, a group of actors that, in the context of an identifiable set of practices, shares the usage of a particular set of story lines over a particular period of time (Foucault 1981; Hajer 1995).

In EU and in German political discourses, sometimes the idea of a knowledge-based economy is used as an implicit concept to bioeconomy, which is a reference to ideas of the knowledge society (see Chap. 3). Most obviously, this concept is interpreted in a way that 'knowledge' is identical to 'scientific knowledge', which reflects the strong roles that scientists are supposed to occupy in the bioeconomy. However, as stated in the first chapter, developing solutions for an innovative and sustainable use of the Earth's limited resources is only one part, the other is to understand and guide targeted societal changes and transformations.

\subsubsection{Addressing Wicked Problems Related to the Bioeconomy Transition}

Bioeconomy discourses claim to address complex societal problems and challenges in which environmental, economic and social dimensions are dynamically interwoven in both, conflictive or mutually enhancing manners. In the literature, this type of challenges is also qualified as 'wicked problems' (Batie 2008). Thus, proposed technological solutions, e.g. the use of renewable instead of fossil material, have to be understood as embedded in new institutional structures (regimes), e.g. consumption patterns, and supported and conditioned by evolving mental frames and knowledge structures, e.g. individually and socially held values and norms, before effectively contributing to the expected social outcomes (efficiency and distribution of costs and benefits). To develop a bioeconomy can be understood as a transition process or a process of social change within societies (Geels 2002) that starts from wicked problems. Such a transition process targets to voluntarily change individual and collective behaviours respective practices of individual and collective actors through the enhancement of problem solving and innovation adoption and diffusion processes (cf. also Sect. 11.1).

To develop a conceptual scheme for such change processes, first, a generic understanding is necessary of what 'a problem' is. Then, we 
Fig. 4.1 Problem solvingbasic structure (adapted from Hoffmann et al. 2009, p. 63)

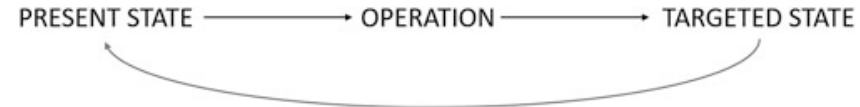

show factors and give examples of what determines a complex or wicked problem in order to demonstrate the multiple aspects to be taken into account. From human psychology concepts, a problem is defined as a perceived discrepancy, a cognitive gap between a desired and an actual state, for which no routinised solution (operation) exists (Hoffmann et al. 2009).

So, a first important insight is that problems are not objectively present but perceived by individuals (=actors) and determined by their subjective understandings and interests. As shown in Fig. 4.1, the basic structure of a problem situation consists of four components: the actual and the desired, targeted state and the operation(s) that may change the actual to a desired state; the fourth component is the feedback loop from the desired future state to the actual state which reflects the assumption how the desired state will influence of the current situation. In other words, it is the expectation about the impact of the desired state. Thus, this step is highlighting that a problem-solving process might not always come to an end when the desired state is achieved (and has become the actual state) (Hoffmann et al. 2009). A problem is given, if one or-what is also possible- - several of these components are unknown to the actor(s).

Analysing the nature of a problem more in detail, its origin may then be caused by either lack of knowledge or by conflicting or incompatible values. As the figure shows, both options may occur in every step, e.g. lack of knowledge may exist with regard to desired state (what should be the share of bio-based materials in the construction sector?) or the valuation of possible desired states and operations (is it ethically acceptable to make use of animals for the production of hormones?). Another challenge may be to coherently understand and address the actual state, e.g. how to judge and assess the current national production of bioenergy? Actors may face great difficulties to address such a challenging quest only on the basis of what is considered 'facts' and might want to consider values and norms, e.g. with regard to the protection of natural resources. Actors may be tied in familiar social contexts in multiple ways. They may ignore relevant information ('group think') or are unable to change behaviour due to normative expectations by reference groups. Also, actors may identify themselves strongly with a certain status quo, so that they are reluctant to change behaviour, which would challenge their status (e.g. diversification of farm activities in order to increase income may be connected with changing gender roles). Finally, problem solving is also a personal cognitive capability. Actors often are overconfident with regard to their own capabilities (skills) and their capacities (e.g. time, money) to solve problems (e.g. car drivers are in general overconfident about their own driving skills). Overconfidence is particularly problematic in risky choice situations (overconfident actors often take higher risks). However, under-confidence in particular with regard to low-status groups (poor, marginalised) may also be possible and lead to a situation where actors do not solve perceived problems despite the fact that they have both the capacities and the capability to act. These various aspects may all contribute to the perception and description of a problem and cause that frequently 'there is no consensus on what exactly the problem is' (Batie 2008, p. 1176) —a typical feature of wicked problems.

Summarising, addressing wicked problems in the context of bioeconomy, requires both an analytical understanding of what the core components of the respective problem are and a synthetic view of how the various mutual understandings of the people engaged with the problem can be related and integrated. An example of an interdisciplinary problem view is 
presented in the excursus box. A conceptual approach of how to develop an integrated understanding is presented in Sect. 4.3 on systems thinking and systems practice.

\section{Box 4.2 Interdisciplinary Problem-Solving Approach (Example)}

For students, it can be especially interesting how the problem-solving approach is explored by other students. Zhang and Shen (2015) introduce an example of 16 interviews conducted with the graduates of 3 disciplinary backgrounds (physics, chemistry and biology) who explain their experience in dealing with 2 interdisciplinary problems on the topic of osmosis. Even though the majority of the students honestly express their sceptical opinion about one or both disciplines in which they are not specialised in, in the end, they admit the value of the interdisciplinary approach in dealing with complex issues:

- Firstly, all scientific fields are interconnected to some extent and 'boundaries between subjects are artificial' (epistemological perspective).

- Secondly, to conceive almost any world problem, a comprehensive view based on many disciplines must be considered (practical perspective).

- Thirdly, interdisciplinarity can serve as a tool which supports the learning process as it gives students an opportunity to see 'a broader picture' regarding a particular problem (educational perspective).

The authors provide the graphs and detailed descriptions of the interviews with quotes (read more-https://doi.org/ 10.1080/09500693.2015.1085658).

As has been argued in the previous sections, the challenge of transition to bioeconomy, of addressing the respective problems appropriately and of responding to questions arising from changing production and consumption patterns not only involves researchers but requires active engagement of many other actors. 'A close communication between politics, business, science and civil society, as well as the preparation of policy decisions' is necessary (BMEL 2014, p. 45). Furthermore, 'a knowledge-based dialogue on controversial issues' has to consider general public's interests and demands (BMEL 2014, p. 47). Spreading awareness about changes and innovations in the society, keeping people informed, 'strengthening open-mindedness' is also important (BMEL 2014, p. 10).

Inter- and transdisciplinary research approaches are considered to have the potential to positively contribute to addressing and working on complex societal problems and to considerably advance the generation of effectively implementable knowledge (Agyris 2005) relevant for innovative solutions. In the following section, these approaches are presented.

\section{Further Reading}

Staffas L, Gustavsson M, McCormick K (2013) Strategies and policies for the bioeconomy and bio-based economy: an analysis of official national approaches. Sustainability 5:2751-2769

\section{Useful Links}

BMEL (Federal Ministry of Food and Agriculture of Germany) (2014) National policy strategy on bioeconomy. Renewable resources and biotechnological processes as a basis for food, industry and energy. http://www.bmel.de/ SharedDocs/Downloads/EN/Publications/NatPo licyStrategyBioeconomy.pdf?_blob=publication File. Accessed 25 Dec 2016

European Commission (2012) DirectorateGeneral for research and innovation. Innovating for sustainable growth: a bioeconomy for Europe. http://bookshop.europa.eu/en/innovating-for-sus tainable-growth-pbKI3212262/. Accessed 12 Jan 2016

OECD (Organisation for Economic Cooperation and Development) (1996) The knowledge-based economy. http://www.oecd.org/ sti/sci-tech/theknowledge-basedeconomy. htm. Accessed 17 Sep 2017 


\subsection{Terms and Backgrounds of Inter- and Transdisciplinary Research}

As argued above, a societal transition to a more sustainable way of production and resource use in the frame of the bioeconomy paradigm requires a successful cooperation of a broad range of actors from various societal subsystems and a meaningful integration of scientific and practical knowledge. Hence, science's contribution to the solution of the problems consists necessarily of multifaceted and integrated approaches, or in short, of inter- and transdisciplinary research (Brand 2000; Hirsch Hadorn et al. 2008). In the following, we briefly present definitions and then elaborate on principles and key characteristics of inter- and transdisciplinary knowledge generation in the context of bioeconomy.

\subsubsection{What Is Meant by Interdisciplinarity, What by Transdisciplinarity?}

At first sight, scientific disciplines seem to be easily separable entities of subject matters, such as biology, chemistry, economics, history, etc., that are shaped by common rules and internally passed down procedures of knowledge generation. However, we also can observe a continuous disciplinary differentiation and itemisation that is expressed, for example, in extended titles of academic chairs. From a social science perspective, scientific disciplines can be considered as institutions that shape the way in which people do research in a certain thematic field and on a range of topics (following Castán Broto et al. 2009). Here, the term institution is defined as a set of conventions, norms and formal rules that 2005, as quoted in Castán Broto et al. (2009). Hence, a discipline is a result of shared understandings, practices and conventions that have been accumulated and compiled over time.

\section{Interdisciplinarity}

Scientific research that relates a number of disciplines and transgresses the broader fields of humanities and natural sciences. (Knierim et al. 2010; Tress et al. 2007)

Doing joint research as a group of researchers with different disciplinary backgrounds is usually denoted as 'multidisciplinary'. Multidisciplinarity refers to a research that addresses a question or an issue from a variety of disciplinary perspectives, without purposefully integrating the various findings. Results of this type of research consist usually of added disciplinary pieces without synergies rather than a connected composition (Pohl and Hirsch-Hadorn 2008a, b). As an example, we see that in the policy strategy 'Innovating for Sustainable Growth: A Bioeconomy for Europe' (2012), the EU develops 12 crucial actions among which one is increasing crosssectoral and multi-disciplinary research and innovation' (European Commission 2012).

Interdisciplinarity involves different disciplinary approaches to research in a conceptually coordinated way where the disciplinarily guiding assumptions and research concepts ('worldviews') are made explicit and mutually connected. Thus, interdisciplinarity implies overcoming classical boundaries and reorganising scientific questions and knowledge (Mittelstraß 1987). With an interdisciplinary approach, 'facts and findings' from each discipline are critically evaluated in light of the 'facts' from the other disciplines, and the attempt is made to integrate discipline-specific knowledge into a larger whole. The broader the range of disciplines involved, and especially if both natural and social sciences' researchers participate, the more challenging is this step of knowledge integration. 


\section{Box 4.3 Examples of Interdisciplinary}

\section{Studies}

A number of applied studies are carried out within the interdisciplinary project 'Spatial Humanities' (funded by the European Research Council) whose main goal is stated as 'developing tools and methods for historians and literary scholars' who use the geographic information systems (GIS). In their research work, the interdisciplinary team combined computational linguistics, cultural geography and spatial analysis. Thus, the project implemented methodologies in an interdisciplinary way that allowed to investigate unstructured material from historical literature and official documents. Visit the project's webpage via http://www. lancaster.ac.uk/fass/projects/spatialhum. wordpress/.

Another example for collaboration of an interdisciplinary team (ecologists, anthropologists and economists) is given by Lockaby et al. (2005). The project WestGa consists of several studies devoted to the 'urban development of forested landscapes' in the Southeastern United States taking into account land use, ecosystems, biodiversity as well as social and policy aspects related to the process. The WestGa projects help to analyse roots and consequences of many-sided issues associated with the 'relationships between urban development and natural resources' and design solutions for them. Read morehttps://www.auburn.edu/ zhangd1/Refereed Pub/Urbanecosystems2005.pdf.

Podestá et al. (2013) describe two interdisciplinary multinational research projects which investigate relations 'between climate variability on interannual to decadal scales, human decisions, and agricultural ecosystems in the Argentine Pampas'. In both cases, the problem-driven cooperative work of the scientists from diverse fields (climate science, oceanography, physics, statistics, agronomy, geography, anthropology, sociology, agricultural economics, psychology, epistemology and software engineering) together with social stakeholders plays the main role in achieving the outcomes. These are 'implementation of new climate diagnostic products, multiple talks and articles for non-scientific audiences, and various tailor-made instructional efforts (e.g., workshops on the fundamentals of decision-making)'. The participants of the projects agree that the intense interdisciplinary collaboration, especially with the involvement of stakeholders (transdisciplinary approach, to be described below), can be very demanding and energyconsuming, starting with the common formulation of a problem, choosing crossdisciplinary methods to be used in research, formation of a team and others. The obstacles stem from differences in 'styles of thought, research traditions, techniques and language' of involved actors. However, despite the difficulties, the interdisciplinary approach facilitates in keeping a systemic view and looking at problems from a range of perspectives. Read more-https://doi.org/10.1016/j. envsci.2012.07.008.

Finally, transdisciplinarity broadens a research's scope into another study dimension as beside the orientation towards real-life problems; this approach also seeks to integrate lay or non-academic knowledge with scientific one. This understanding is expressed in the definition of Lang et al. (2012, p. 27) where 'transdisciplinarity is a reflexive, integrative, method-driven scientific principle aiming at the solution or transition of societal problems and concurrently of related scientific problems by differentiating and integrating knowledge from various scientific and societal bodies of knowledge'. 


\section{Box 4.4 Example of Transdisciplinary Research}

On the challenge of adapting agricultural systems to the effects of climate change, Bloch et al. (2016) show how farm-specific innovations and adaptive measures are developed in a transdisciplinary research approach. In a cyclical process of analysis, planning, action and reflection, the network of researchers and organic farmers repeatedly used participatory analyses tools to structure the transdisciplinary innovation and adaption process. First, a group of organic farmers identified as main weaknesses the water and nitrogen supply likely to be worsened by climate change; then, farm-specific adaption measures were identified and tested by conducting on-farm 27 experiments at 6 organic farms in teams of researcher and practitioners. By evaluating and thus adjusting and retesting the measures in consecutive trials, new farming methods were developed to increase diversification and decrease risk in organic farming practices. Along with the iterative process, the network was expanding towards actors from advisory services and farmers' associations, and the collective learning process led to changes in attitudes and behaviour. The participating organic farmers proved to be active partners; their openness to innovation and their approach to problem solving make them well suited to transdisciplinary research. In adapting regions to climate change, these kinds of stakeholders will play a decisive role. https://doi.org/10.1007/ s13165-015-0123-5

\section{Transdisciplinarity}

A specific form of interdisciplinarity in which boundaries between and beyond disciplines are transcended and knowledge and perspectives from differrent scientific fields as well as non-scientific sources are integrated (Bergmann et al. 2010).

Thus, the interface between society and science is a key constituent which implies not only the necessity to create mutual understandings but to go far beyond towards interaction and collaboration among the various actors.

Rosenfield (1992, p. 1351) revealed a narrower understanding when she defined transdisciplinarity as "jointly work of researchers using shared conceptual framework drawing together disciplinary-specific theories, concepts, and approaches to address common problems'. Clearly, this definition is almost similar to the above developed description of 'interdisciplinarity' and points at the difficulty that, in some scientific communities, the terms are blurred and no clear distinction is made in this regard. However, nearly 25 years later, a certain stock of transdisciplinary publications can be acknowledged which also allows to summarise 'three core features of transdisciplinary research: (1) complex real-world problems, (2) collaborations, and (3) evolving methodologies' (Zscheischler and Rogga 2015, p. 32).

Finally, we conclude the range of definitions with a more pragmatic one given by Jahn et al. (2012, p. 4): 'A reflexive research approach that addresses societal problems by means of interdisciplinary collaboration as well as the collaboration between researchers and extra-scientific actors; its aim is to enable mutual learning processes between science and society; integration is the main cognitive challenge of the research process'. Definitions have the important function in academia to standardise understandings and by this provide a solid common ground for cooperation. Nevertheless, there may be contested or conflicting perspectives within a group of scientists. Hence, the search for a common definition is important in order to determine agreements, but also differences in looking at the world and explaining phenomena. Consequently, for an inter- or transdisciplinary team, it is important not to impose common definitions 
but to deal with definitions in a flexible way and to explore and identify the "common epistemological ground, i.e. the common conceptual understanding of cause-effect relations. The multifaceted systems theory is well suited to structure this working step (see Sect. 4.3).

\subsubsection{Backgrounds of Inter- and Transdisciplinary Research}

There is an increasing concern about the usability of research outputs and a quality divide between lay and scientific knowledge is contested. Instead, there is a growing conviction that solving real-world problems requires the integration of multiple forms of knowledge. This includes the acknowledgment of practical, local, tacit knowledge as a valuable resource but in particular also the integration of social and natural sciences perspectives.

Previously, the emergence of modern science was closely connected with the development of modern societies. The paradigm of scientific discovery had become the dominant mode of innovation in the modern world. It was built on the hegemony of theoretical and experimental science, and sometimes science has been seen as the only location of innovation and discovery. This model of science is built on a set of principles, such as the autonomy of scientists, which is also considered being the basis for internally driven taxonomy of disciplines, the ability of purely scientific problem definitions and the assumption that scientific knowledge is objective and can be used irrespective of the context. Although this model has been fundamentally contested already (e.g. Kuhn 2012), it is still widely prevailing in both academic communities and the interested public.

The paradigm of scientific discovery is closely connected to transfer of knowledge or transfer of technology (TOT) model that assumes a one-directional diffusion of new knowledge and innovation from science to other parts of society (Hoffmann et al. 2009). This paradigm and the corresponding model of diffusion of innovation has been criticised on various occasions (e.g. Hoffmann 2007). In a groundbreaking ethnographic study (The Manufacture of Knowledge), Knorr-Cetina (1981) demystified science. She demonstrated that science is not a purely rational, cognitive process, but scientific knowledge is a social process and practice which is embedded in a trans-scientific field. Researchers have to make series of choices (about research objectives, methods, sampling, publishing strategies etc.) that are bound to social factors (e.g. external evaluators, local research traditions, funding opportunities). Thus, science can be studied like any other social field, and in particular, the assumption of science providing objective, transferable and decontextualised, all-round applicable knowledge has to be taken with caution. Further examples for pioneer research on knowledge generation outside science were provided by Karl Polanyi (1886-1964) and Clifford Geertz (1926-2006) who worked on tacit and on local knowledge. Tacit knowledge is defined as knowledge that is difficult to transfer to another person by means of writing it down or verbalising it ('we can know more than we can tell'), so it is opposed to explicit knowledge. Examples are all handicrafts, where actors may develop incredible skills, which can only be learnt through practice. Local knowledge can be understood as a shared way of interpreting the world and, thus, relates to basic ideas of social constructivism (Geertz 1973). Here, the meaning of 'local' is not defined precisely but relates knowledge to people, places and contexts. Since knowledge is always culturally bounded and thus socially constructed, there is no universal knowledge; hence, the universality claim of scientific knowledge is questioned; and science is considered as a social practice, among others (Knorr-Cetina 1981). As a consequence, there may be different worldviews, and thus, 'knowledge' and projects that support social or societal change may become 'battlefields of knowledge' (Long and Long 1992), in which competing interpretations of reality struggle to become the orthodox or dominant view. 
Table 4.2 Expert versus lay knowledge (compilation of the authors)

\begin{tabular}{l|l|l} 
& Expert (scientific, explicit) & Lay (local, personal, tacit, practical, traditional) \\
\hline Context & Decontextualised & Contextualised/situated \\
\hline Epistemology & Objective & Socially constructed \\
\hline Generation & Systematic research/science & Practical experience \\
\hline Codification & Highly codified & Uncodified/tacit \\
\hline Valuation & Academic discourse & Communities of practice \\
\hline Roles & Experts & Practitioner \\
\hline Policy approach & Top-down, exogenous development & Bottom-up, endogenous development \\
\hline
\end{tabular}

The different types of knowledge are often condensed in a dualistic typology of expert versus lay knowledge (Table 4.2).

\subsubsection{Acknowledging Preconditions and Bases of Inter- and Transdisciplinary Research}

Transdisciplinary research has a relatively young history: In Germany, it was especially the increasing (political) request for sustainability research which encouraged and strengthened inter- and transdisciplinary research approaches. Starting from the late 1990s, a series of correspondingly targeted calls and programs from the German Ministry of Education and Research (BMBF) can be noted, and the first prominent projects were related to agricultural landscape research (Müller et al. 2002; Hoffmann et al. 2009). Also, in Austria and Switzerland, largescale transdisciplinary research programs were funded, and, step by step, a certain body of common understanding, principles and core approaches was discussed in books and papers (Brand 2000; Hirsch Hadorn et al. 2008; TA 2005; GAIA 2007). At that time, several authors noted general deficits in the philosophy of science and epistemological basis related to interand transdisciplinarity; Grunwald and Schmidt (2005, p. 5) lamented that 'a lot had been said about inter- and transdisciplinarity, some has been practiced, little is reflected and understood'; they called for methodological canonisation and routines.

The number of sustainability-related interand transdisciplinary studies has drastically increased since then and international journals publishing such research have become more widespread, such as 'sustainability' or 'ecology and society'. However, most frequently, papers report on experiences from single projects and describe case studies while comparative or even quantifying research is still at its beginning (Schmid et al. 2016; Zscheischler and Rogga 2015).

From the presented definitions and their conceptual foundations, we can conclude that mutual understanding and joint conceptual bases appropriate to cross-disciplinary boundaries are necessary constituents for successful inter- and transdisciplinary approaches. In the following section, systems thinking and systems practice are introduced as theoretical concepts and practices with the aim to support inter- and transdisciplinary teams in joining and relating interests, objectives and understandings for successful cooperation.

\section{Further Reading}

Hirsch Hadorn G, Hoffman-Riem H, BiberKlemm S, Grossenbacher-Mansuy W, Joye D, Pohl C, Wiesmann U, Zemp E (2008) Handbook of transdisciplinary research. Springer, Dordrecht

Lang JD, Wiek A, Bergmann M, Stauffacher M, Martens P, Moll P, Swilling M, Thomas CJ (2012) Transdisciplinary research in sustainability science: practice, principles, and challenges. Sustain Sci 7(1):25-43

Zscheischler J, Rogga S (2015) Transdisciplinarity in land use science-a review of concepts, empirical findings and current practices. Futures 65:28-44 


\subsection{Systems Thinking, Systems Practice}

\subsubsection{Systems Theory}

Systems theory is a disciplinary transgressing idea for the study of the abstract organisation of phenomena, independent of their substance, type or spatial or temporal scale of existence. It investigates both the principles common to all complex entities and the (usually mathematical) models which can be used to describe them. We propose to use systems analysis as an abstract way to conceptualise how various world views and understandings can be connected in transand interdisciplinarity research projects. Systems thinking thus provides the necessary bases for linking multiple sources of knowledge and some general concepts that help to reflect and structure transdisciplinary research. In the following, we give an eclectic overview based on economic, sociological and natural sciences' conceptualisations of systems (Huber 2011; Schiere et al. 2004).

Generically, systems consist of basic elements, which may be of a similar type (e.g. humans in human societies) or different types (e.g. animal and plants in an ecosystem). The elements of a system are connected to each other by specific relations or forms of interactions (e.g. communication, predator-prey relations, information, energy and material flows). Any relationship can be interpreted as a form of communication and exchange of information. Any communication requires a signal and a receiver. The receiver will respond to the signal in one way or another. Communication does not necessarily imply awareness or consciousness. In technical systems, the components communicate among each user even though they are not aware what 'they are doing'. Instead, a sensor perceives a signal. In the case of living systems, this may require the ability of elements to identify and select among different behaviours and/or states of other elements (information processing). Relations therefore are selective in the way that certain states are recognised and others are ignored. An example for a living system is given in the excursus box below.

\section{Box 4.5 The Fox-Mouse Predator-Prey} Relation Perceived with a System Concept In the fox-mouse relation, the only relevant information for a fox is the availability of mice (yes/no coded as 0,1 ). Further properties of mice are irrelevant (e.g. gender, personal character, family status, age). The availability of mice is not a signal that mice intend to send. The information about the availability of mice will influence the reproduction behaviour of foxes. This will again have an effect on the presence of foxes, which will have an impact on the availability of mice. The fox-mouse relationship may be understood as a subsystem in a wider ecosystem.

Thus, information can be described as perceived data, to which meaning is ascribed by the element (Schiere et al. 2004). Information processing has an effect in the way that certain states or behaviours will trigger sequential operations. However, a system only emerges, when the response of receiver will be observed by the original sender and or other elements of the system, and this reciprocal communication will be reproduced over time. Only then, systems form identifiable entities that can be clearly separated from their context, the system's environment. The separation of systems and their environment requires the existence of boundaries.

Systems thinking has proven its usefulness as a general meta-theoretical approach that seeks to depart from linear thinking in order to model complexity. Initially, it extends the model of simple causation (cause-effect) by introducing feedback loops (reciprocity) and linkages to other entities. Feedback loops and linkages between several elements are necessary but not sufficient to characterise a group of elements as systems. In systems, the elements interact in ways that new collective patterns and regularities 
emerge such that larger entities hold properties the individual elements do not exhibit ('the system is more than the sum of its part'). This phenomenon is usually referred to as emergence.

Thus, systems thinking provides a huge potential for transdisciplinary research as it offers options to connect phenomena of different kinds. Usually, this connection implies a hierarchy in the sense that systems are constituted by elements, which are of a different kind. The connection is referred to as 'structural coupling'. Emergent systems are structurally coupled with the entities, on which they are built. Structural coupling describes a nondeterministic relationship, in which the emergent system does not recognise the existence of the lower-order entities. For example, the human consciousness and cognitive abilities are based on neurobiological processes. However, what we think is independent from the neurobiological processes (nondeterminism) and, at the same time, our consciousness is unable to observe that the neurons of our brain are working (Fig. 4.2). For the study of wicked problems in bioeconomy, such a system understanding is relevant as it enables people to connect the material phenomena related to bio-based technologies (e.g. bioinformatics resulting in the possibility

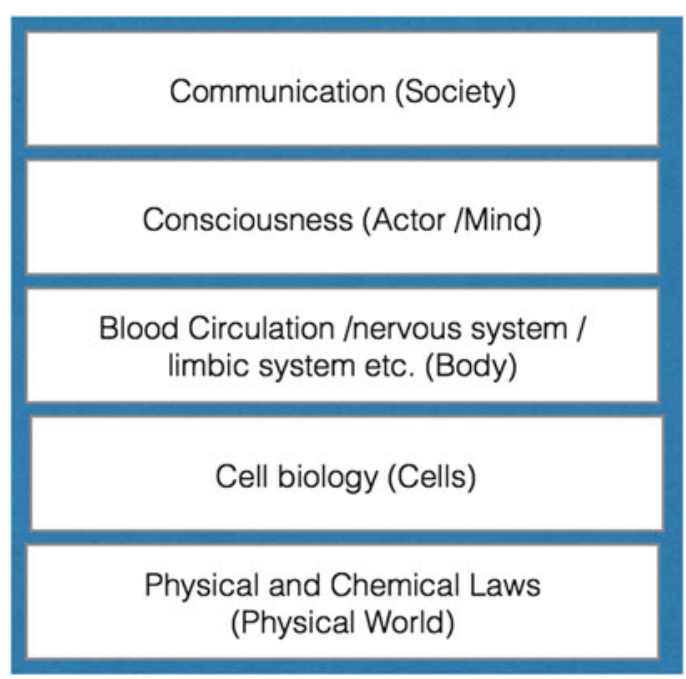

Fig. 4.2 Example for emergent phenomena of monitoring and steering living organism) to interpretation and sense-making of human activities (here: institutions and ethics of bio-engineering) and by this to relate technological change to pathways of societal transformation.

In sum, we can describe systems as emergent entities with identifiable boundaries, in which the elements are linked in reciprocal ways, which are structurally coupled to its elements, and that can be nested in larger systems and/or consist of subsystems.

\subsubsection{Differentiating Systems}

As it has been mentioned in the beginning of this section, system analysis is a way to address complexity. Systems can be distinguished regarding their own complexity. The complexity of systems is associated with the attributes of its elements, relations as well as the system-context relations. Due to the disciplinary multitude of systems theories, there are many ways of how to differentiate the system notion. In the following, we present a few attributes that commonly serve for differentiating systems and which are of use in the context of inter- and transdisciplinary research.

\section{Openness}

One way to categorise systems is about their openness or the closure of a system's boundaries. In engineering, closed systems are such, for which required inputs and/or outputs are controlled. Examples of closed systems:

- A computer network is closed in the sense that digital data transfer is only possible between a defined set of computers, while energy and user input is required.

- A greenhouse can be organised in a way that no water and nutrients can escape (matter); thus, it is an independent, self-sufficient entity; however, at the same time, heat (energy) is constantly exchanged with the environment (Fig. 4.3). 
Fig. 4.3 Greenhouse, a closed system (the University of Hohenheim, photographer Sacha Dauphin)

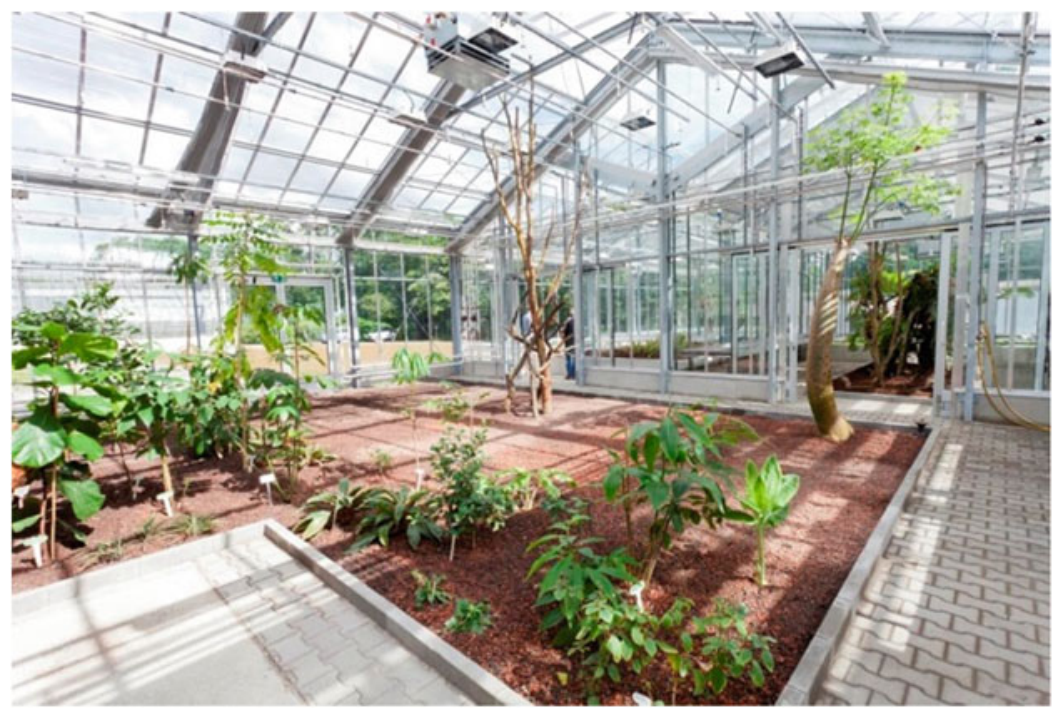

Fig. 4.4 Shift from closed

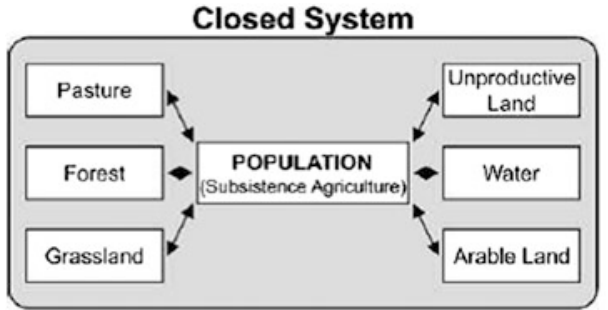

system to open system

(Messerli and Messerli 2008)

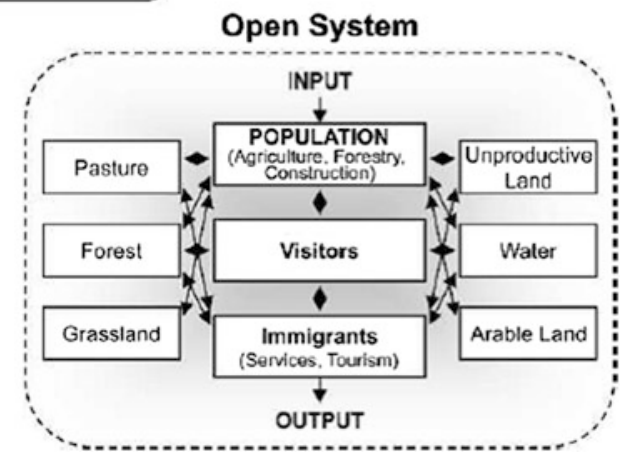

An open system is a system that has external interactions with its environment also for its core relationships. Hirsch Hadorn et al. (2008) provide an example of a change from rather closed rural system (1860) to an open one (twentieth century) during the society's development and modernisation over time. Because of the flows 'of people, capital, energy, technology, information, goods and services in many different forms', linkages in the land use system behave in a more complicated way, and even areas considered as conventionally 'unproductive' are used more and more often, e.g. for tourist and conservation purposes (Fig. 4.4).

Leakages in both directions, emissions and absorption of matter or information, may have a 
significant effect on system performance. Thus, boundary maintenance is commonly both a core issue of evaluation and assessment, and an intervention strategy. Technological approaches in the bioeconomy that seek to improve productivity and sustainability usually try to reduce openness of production systems by creating closed systems to gain direct control over emissions and absorptions. However, such direct interventions are in many situations not possible or cause other adversities. Then, only indirect approaches of system steering are possible. Transdisciplinary research is closely related to situations, in which the openness of system boundaries must be maintained since the negative externalities of closure may exceed its benefits.

\section{Goals and Functions}

Another way of looking at systems is focussing on systems' goals or functions. Goals are states that systems try to achieve and maintain, despite obstacles or perturbations. There are mainly two contexts when goals are commonly labelled functions. Firstly, in diversified systems like organisms, subsystems may provide a specialised function to the maintenance of the whole. Here, function is connected to division of labour. Secondly, functions of systems may be ascribed goals. For instance, ecosystem services or the function of a machine are no entities of the system itself but ascribed to the systems by humans. In such cases, assessments of system performances may tell us as much about humans who assess as about the system performance itself. The term 'goal' is more commonly applied, when some degree of intentionality is assumed. Particularly, human social systems (e.g. organisations) are often treated as goaloriented entities. In contrast, physical systems (e.g. planet system or atoms) are usually considered as unintentional, in the way that they are solely determined by physical laws. Describing things in terms of their apparent purpose or goal is called teleology. Regarding system assessment, we find that in biology, the evaluation focus is shifting away from outputs and inputs towards persistence and maintenance over time.
This shift is connected to a specific characteristic of living and ecological systems that is called autopoiesis. Autopoiesis refers to a system capable of reproducing and maintaining itself (selforganisation). The components (elements/ subsystems) of such system are produced by internal components or through the transformation of external elements by internal components. For example, a bee colony is an autopoietic system that internally reproduces its elements (queen, drones, worker bees (house bees, guards, field bees), bee hive) and actively transforms external components (nectar, pollen, etc.) to components (feeding, building material).

Autopoietic systems are operatively closed in the sense that certain internal operations are required to maintain the system. Systems structures are built and modified by internal operations. More importantly, autopoiesis is connected with the ability to adapt to environmental changes (adaptive systems). This requires sensory feedback mechanisms and the development of an adaptation that is a change of behaviour patterns and/or structural changes. In the example, a bee colony is storing honey and reduces its size during winter as a response to seasonal food availability. The opposite of autopoiesis is called allopoesis. A car factory is an allopoetic system that uses raw materials (components) to generate a car (an organised structure), which is something other than itself (the factory). Autopoietic and allopoetic systems rely on a distinction that goes back to biologists and systems thinker Hugo Maturana (born in 1928) and Francisco Varela (1946-2001).

\section{System Assessment}

This focus on survival, self-organisation and adaptivity in the study of living and ecosystems has triggered the debate on a different types of assessment criteria such as equilibrium, stability and resilience that also have been influencing other sciences, particularly, economics (think of the idea of market equilibriums in general economy) and sociology (Table 4.3). The concept of system equilibrium is perhaps the oldest approach applied. An equilibrium is a state in which all forward reactions (flows, potentials) 
Table 4.3 Characteristics of equilibrium, stability and resilience (compilation of the authors based on Schiere et al. 2004)

\begin{tabular}{|l|l|} 
Equilibrium & $\begin{array}{l}\text { All forward reactions (flows, potentials) equal all reverse reactions, so that the state of a system } \\
\text { remains stable } \\
\text { May only be achieved in closed systems }\end{array}$ \\
\hline Stability & $\begin{array}{l}\text { An absence of excessive fluctuations of outcomes } \\
\text { Outcomes of systems remain in a defined range of parameters }\end{array}$ \\
\hline Resilience & $\begin{array}{l}\text { Capacity of an (eco)system to respond to a perturbation or disturbance by resisting damage and } \\
\text { recovering quickly }\end{array}$
\end{tabular}

Table 4.4 Simple and complex systems (based on Schiere et al. 2004)

\begin{tabular}{|l|l|l|}
\hline \multirow{2}{*}{ Elements } & Simple & Complex \\
\hline Interactions/relations & Small number of elements & Large number of elements \\
& Attributes of the elements are predefined & Element attributes are variable \\
\hline & Few interactions & Many interactions \\
\hline Linear interactions & Non-linear interactions \\
\hline Elements are loosely coupled & Elements are strongly coupled \\
\hline Subsystems & No feedback loops & Feedback loops \\
\hline Boundaries & Simple relations & Multiplicity of relations \\
\hline Time & Few, simple subsystems & Nested, complex subsystems \\
\hline
\end{tabular}

equal all reverse reactions, so that the state of a system remains stable. However, such a state may only be achieved in closed systems. A more moderate concept, stability, thus has been applied to highlight the absence of excessive fluctuations of outcomes. In this sense, outcomes of systems remain in a defined range of parameters. However, these concepts are more important for engineering and the physical world. Ecosystem resource has shown that outcomes may vary considerably, and, if they vary, radical shifts may occur not only due to external shocks but as a normal condition (consider summer and winter aspects of ecosystems in the North or the dry season/rainy seasons in the South). For the analysis of such systems, the concept of resilience has been widely adopted. It is defined as the capacity of an (eco)system to respond to a perturbation or disturbance by resisting damage and recovering quickly (Schiere et al. 2004).

Table 4.4 presents selected opposing characteristics in a simplified way. To make this distinction operational, qualities such as 'small' or 'large' number or 'few' or 'many' interactions would need quantification. The more complex systems, the more direct interventions will induce side effects, and the less they are likely to succeed.

Finally, one debate connected with systems approaches is that about the ontological status of a system. There is a position that systems are 'real'. Thus, a system is understood as existing in the real world; it has ontological status, i.e. exists independent from an observer. The alternative viewpoint is that systems are analytical constructions by the observer. The elements, relations and boundaries of the system are defined by the observer, who has a certain interest in the analysis. Thus, systems can be considered as systems of interests. Science or any other societal community define system perspectives to analyse certain types of problems. In this sense, systems are socially constructed entities (by a group rather than by an individual).

For example, from a biological perspective, it seems at a glance self-evident that the human is defined by the boundaries of the body. However, the body is settled by microbes that may be both dangerous (e.g. viruses) and helpful (e.g. millions 
of bacteria that support our digestion) but are inside of our body. Such a definition also excludes the fact that we rarely meet naked humans. So, does the clothing that definitely is functional under certain climatic conditions belong to a 'real definition' of being human? From a psychological viewpoint, a definition of being human includes the concept of personality that comprises its cognitive abilities, the character and patterns of behaviour. According to systems thinking, human culture can be understood as an emergent phenomenon that is structurally coupled to the biophysical world (Fischer-Kowalski and Weisz 1999). In the field of socio-environmental studies, the interfaces of human-nature relations have become particularly important. Frameworks to analyse socioecological systems include entities such as nature objects, materials, etc. as well as humans and social systems (cf. Sect. 4.3.4).

\subsubsection{Systems in Social Sciences}

So far, most research for the bioeconomy is in natural and engineering sciences. However, as a research approach that fundamentally aims at changing societal phenomena and conditions (transformation), transdisciplinary research projects are undertaken to change perceptions, knowledge and behaviour of human beings, thus targeting social systems. Moreover, transdisciplinary research projects themselves are social systems, in which groups of individuals communicate in order create new knowledges and to solve complex socioecological and sociotechnical problems (cf. excursus box in this section). Therefore, we introduce two approaches in social sciences, which have applied systems thinking to the analysis of societal problems.

\section{Social Systems as Action Situations}

The American Sociologist Talcott Parsons (1902-1979) has introduced systems thinking to sociological analysis (Parsons 1991[1952]). His concern was the analysis of social action. An action is a special type of behaviour that is related to some subjective meaning or intention. Even further, a social action refers to an 'act' which considers the actions and reactions of other individuals. Thus, according to Parsons, the basic elements of a system are 'acts'. An act requires an actor, an end/outcome, a future state of affairs towards which the process of action is oriented and an action situation, which is defined by 'conditions' of action, and actors' 'means', and that allows alternatives or choices. The latter implies that actors' individual orientations are relevant. Actions are usually not isolated events but must be seen in relation to the actions of other individuals. Thus, a 'social system is a system of processes of interaction between actors, it is the structure of the relations between the actors as involved in the interactive process which is essentially the structure of the social system. The system is a network of such relationships' (Parsons 1991[1952], p. 15).

One important point is that social systems develop stable patterns that are rather independent from the individual actors. Through stable patterns emerging from repeated interactions, rules or norms evolve. In more complex social systems, such norms become generalised, appear as collectively shared knowledge and form complex normative structures rather independent from individuals. Thus, social systems are emergent phenomena, which are constituted by norms, roles and institutions. From the perspective of an individual, the social systems appear as given structures. Actors will orient their actions not only towards action outcomes, as utilitarian (economic) theories suggest, but actions will also follow a normative orientation taking third-party actions and expectations into account. Parsons thus distinguishes motivational orientations that refer to needs and benefits of individuals and normative orientations.

Since there are many possible action situations, actors face the problem to interpret situations, to know, which rules to apply. Therefore, actors must share knowledge and understand signs and symbols, which help to identify the nature and the meaning of situations. These shared knowledge and beliefs and the expressive 
symbols together form the cultural system. Thus, values, beliefs and symbols must be considered in the analysis of social action situations. Referring to our former discussion, one could say that the cultural system is the basis for information flows and communication process in social systems.

Like the social system, the cultural system provides comparatively abstract structures that from the perspective of the individual may appear as given. While social structures provide institutions, Parsons calls cultural structures of symbolic signification generalised media of interaction. The prototype and most highly developed example of generalised media of social interaction is language. Parsons argues that social action situations can be seen as (action) systems, in which the personal, the social and the cultural systems are tied together and interpenetrate each other. At a later stage, he added the biological organism as a fourth system. All systems shape action situations by providing orientations (motivations, normative expectations, values, instincts) as well as structures (abilities/resources, rules, media, physical conditions).

\section{Social Systems as Communication Situations}

While Parsons developed his systems theory starting from the analysis of social action situations, the German sociologist and systems thinker Niklas Luhmann (1927-1998) has shifted the perspective to the analysis of the reproduction of social systems (Luhmann 2013). One could say, while Parsons is focussing on the single acts and social organisations at a given point in time, Luhmann is interested in the perpetuation and continuation of social processes in the flow of time. Central to his analysis is the connectivity of events. Rather than to ask how systems shape actions, he asks how systems emerge out of individual acts. Thus, his concern is less about the person that acts but more about the other actors that observe, interpret the act and may react or do not react. Accordingly, the central element of systems is not action but communication.
Communication does not necessarily imply that observers have to respond to the initial 'actor' directly. For instance, if a player of your favourite football team scores, thousands of spectators will shout; some might hug their neighbour, the goal will be discussed at homes, in the media and your work place; betters will lose or win; and football fans might engage in violent disputes. Thus, an initial act may initiate further, rather diverse activities and outcomes. But how are these activities connected? The answer is shared meaning. All the diverse reactions and following communications and activities require that actors understand the meaning of the goal (even it might be difficult to explain it). Thus, social systems are 'systems of meaning'.

Luhmann's concept of social system deviates from Parsons' model in another important regard. It focusses on the separation of system and environment and emphasises the concept of autopoiesis. Communication is the operation that reproduces specific social systems. Social systems are a continuous flow of related, meaningful communication. Communication creates connected communication, or communication 'produces' new communication. In this sense, social systems are autopoietic, since system elements reproduce its elements. The boundaries of a social system are not physical but are produced and reproduced in a communication situation itself. The evaluation criteria are thus moving away from outcomes and stability towards boundary maintenance and resilience. Meaning can be understood as mechanism to select communication and to define criteria to further maintain, continue and reproduce it. Alternatively, one could say that systems refer to a specific rationale or internal logic where communication requires knowledge about the meaning of a communication as well as communication rules. The reproduction of meaning through communication also requires that meaning must be recognisable. For instance, academic disciplines are subsystems of the academic system, since they share a common rationality of science (the difference between true/not 
true), but have established different research focusses, methodologies, specialist languages and forms of communication.

For Luhmann, communication media are particularly important, and he distinguishes between circulation media and symbolically generalised communication media. Circulation media (oral speech, writing, modern telecommunication, etc.) define the form of communication. The most important aspects of circulation media are the boundedness or separation of communication from time and space and therewith the actors, which can be included in a communication system. Symbolically generalised communication media (SGCM) or success media are important to motivate actors to engage in communications, particularly when these are connected with partly negative consequences. SGCM are binary coded which allows a binary distinction between systems. The main social systems are the political system (binary code power/no-power), economic system (money/no money), science (truth/false) and law (legal/illegal).

\section{Box 4.6 Transdisciplinary Research} as a Communicative Interaction System

The following example will help to explain Luhmann's understanding of social system: A transdisciplinary research project on a bioeconomy-related issue brings people together from different 'backgrounds' (academy, businesses, policy, etc.). Such backgrounds may be understood as different social systems, which follow different rationales. Academics seek for truth (according to their disciplinary standards), business people will look at issues assessing implications for profits and policymakers judge the process from the perspective of maintaining/gaining political power. The transdisciplinary research is not a social system itself but rather an interaction system, in which different systems overlap and constitute a temporary social structure.
The circulation media used are oral communication in meetings, written documents, maps, images or calculations produced by the participants. The use of these media can be very demanding for some, who 'in their worlds' apply different media or media in a different way. Due to the diversity of viewpoints and ways to use media, there is a considerable chance that communication might fail. Project participants may not understand each other and get frustrated or conflicts may evolve.

This interpretation of a transdisciplinary project gives some hints, what kind of issues should be addressed and how results should look like. Firstly, the group has to acknowledge and accept the differences. The process is about understanding the diversity of viewpoints, knowledges, languages and motivations. After the project, everybody will return to his or her own world and must live with the outcomes. Thus, solutions must be designed in ways that they create connectivity between formerly separated worlds, without changing (too much) the worlds (business people will continue to seek for profit, academics for higher reputation and policymakers for voters) (cf. Sect. 4.4).

Summarising, it can be concluded that systems theory is a powerful and extremely productive conceptual approach in the sense that it set manifold impulses for the creation of linkages and the integration of knowledge among various disciplines and groups of professional actors. Hence, systems theory is considered as a key ingredient. Systems-theory-based conceptual frameworks can provide a solid basis to interand transdisciplinary research. In the next section, we demonstrate how system concepts are applied in interdisciplinary research practice, making use of two prominent examples. 


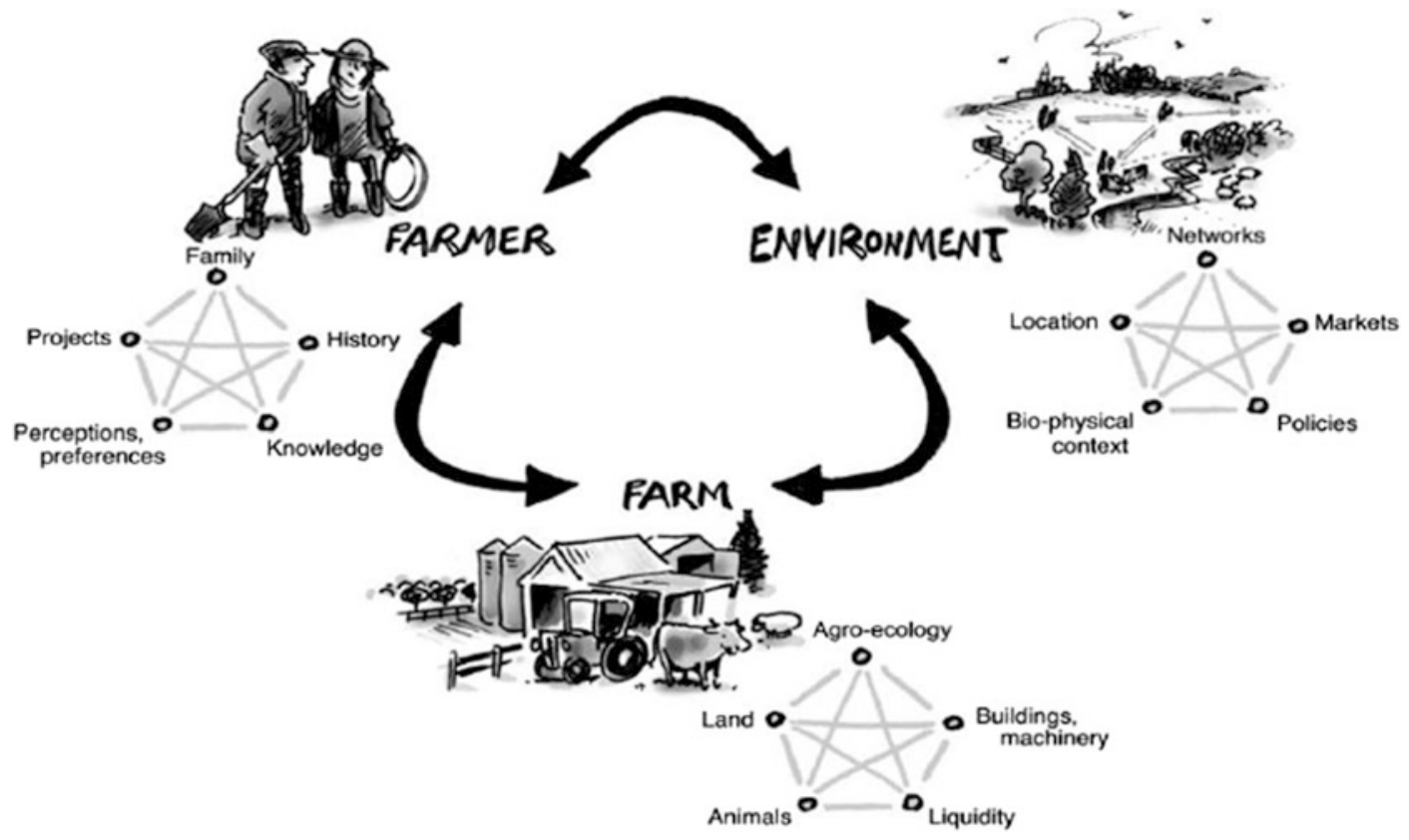

Fig. 4.5 Farming systems approach (Darnhofer et al. 2012, p. 4)

\subsubsection{Systems Practice}

How system concepts are put into research praxis and provide a conceptual framework for interand transdisciplinary research is demonstrated with the help of examples from two scientific communities, the farming system research community and the Ostrom Workshop at the Indiana University of Bloomington.

\section{The Farming Systems Approach}

The farming systems approach proposes an analytical framework combined with a methodological approach in the field of agricultural sciences in order to understand the interactions between components of farms or larger agricultural systems. The components may include material objects (e.g. soils, plants, animals, buildings, financial means, etc.) as well as subjective perceptions, values and preferences, i.e. how farmers 'make sense' of their practices. The focus on interactions also emphasises that a farm cannot be studied in isolation, and to understand the farming practices, the farm needs to be understood as embedded in a territory, a locale and a region, with its specific agro-ecological setting, economic opportunities and cultural values (see Fig. 4.5).

The farming systems approach has three core characteristics:

- It uses systems thinking. Situations deemed 'problematic' are understood as emergent phenomena of systems, which cannot be comprehensively addressed by using only a reductionist, analytical approach. It requires thinking about the interconnections between a system's elements, its dynamics and its relation with the environment. It studies boundaries, linkages, synergies and emergent properties. The aim is to understand and take into account interdependencies and dynamics. It means keeping the 'bigger picture' in mind, even when a study focusses on a specific aspect or subsystem.

- It relies on interdisciplinarity. Agronomic sciences (crop production, animal husbandry) are working closely with social sciences at micro- and mesoscale levels (sociology, economics, political sciences, human geography, 
landscape planning, etc.). Farming systems research is thus distinct from multidisciplinary research, which can provide complementary insights (e.g. informing the development of new production methods).

- It builds on a participatory approach. Integrating societal actors (farmers, extension agents, civil society organisations, associations, etc.) in research is critical to understand 'real-world' situations, to include the goals of various actors and to appreciate their perception of constraints and opportunities. The participatory approach also allows integrating local and farmers' knowledge with scientific knowledge, thus fuelling reciprocal learning processes (Darnhofer et al. 2012; Janssen 2009).

Farming systems research explicitly strives to join the material-technical dimension and the human dimension of farming. The aim is to take into account both the 'things' and their meaning. This requires understanding the structures and the function of systems simultaneously as 'objective' (things, and their interactions, existing in a context) and as 'subjective' (i.e. relating to the different socially contingent framings).

\section{The Socioecological Systems Approach}

A comprehensive understanding of complex human-natural resources' interaction especially at a regional scale and involving collective decision-making and governance issues was the core interest of Elinor and Vincent Ostrom and continues through the "workshop in political theory and policy analysis' in Indiana University Bloomington which they initiated. This community of researchers uses socioecological systems (SES) approaches as analytical frameworks that support the understanding of environmental degradation problems such as an irrigation-related, regional drop of the water level, the depletion of coastal fish sources or soil erosion related to harmful agricultural practices as complex issues. 'Characteristically, these problems tend to be system problems, where aspects of behaviour

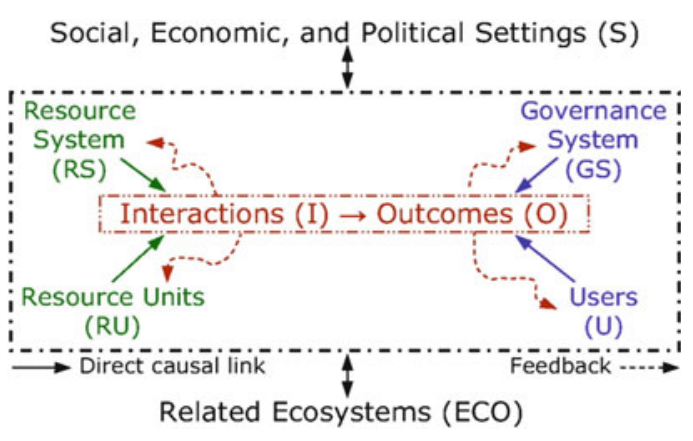

Fig. 4.6 SES (Ostrom 2007, p. 15182)

are complex and unpredictable and where causes, while at times simple (when finally understood), are always multiple. They are non-linear in nature, cross-scale in time and space, and have an evolutionary character. This is true for both natural and social systems. In fact, they are one system, with critical feedbacks across temporal and spatial scales' (Ostrom 2007, p. 15181).

SES frameworks are built around the analysis of action situations similar to those defined by Parsons (Sect. 4.3.3). They have been developed in order 'to clarify the structure of an SES so we understand the niche involved and how a particular solution may help to improve outcomes or make them worse. Also, solutions may not work the same way over time. As structural variables change, participants need to have ways of learning and adapting to these changes' (Ostrom 2007, p. 15181). Figure 4.6 summarises the influencing factors at a very high level of aggregation into an analytical framework that seeks to define common characteristics of SES and to draw on both social sciences as well as natural sciences.

Similar to the farming systems research framework, the generic SES framework (1) relies on systems thinking appropriate to address complex governance problems and (2) makes use of a range of disciplinary expertise that is interdisciplinary combined. While there is no explicit mention on whether and how participatory methods and stakeholder involvement processes are to be included, it gives very detailed instructions for a multilevel governance understanding and analysis of nested action systems and institutional 
Fig. 4.7 Systems practice in interdisciplinary research (Ison 2010, Fig. 4.3.4; adapted from Checkland 1999 and Checkland and Poulter 2006, Fig 4.1.9)

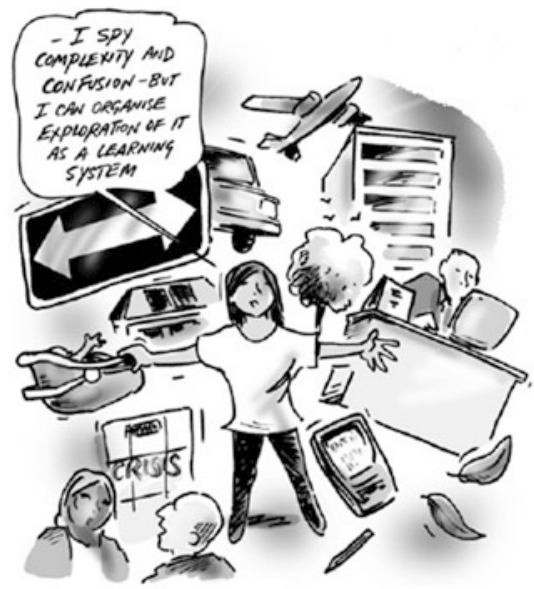

arrangements. By this, the framework is appropriate to substantiate conceptual reflections in transdisciplinary teams addressing societal transition towards sustainable development.

\subsubsection{Making Systems Practice Effective}

Although uncontestably, developing a systems concept is a key constituent for a comprehensive appraisal and analysis of a perceived challenge, it is only one ingredient to systems practice despite others. As shown in Chap. 11, a broad range of key competences is related to professionals in bioeconomy. Here, we concentrate on those important in the context of research and follow Ison (2012), who emphasises the important role (s) and agency of the researchers engaged as system practitioners. Especially, it is the researcher who makes conceptual and definition choices and determines by these possible outcomes. Ison (2012, p. 145) stresses that (1) reflection about such steps in the making of research and (2) reflexivity about 'why we do what we do' are essential to link the researcher's perspective with the 'situation outside of our selves' (Ison 2012, p. 147). Thus, reflexivity is necessary in order to understand one's role in contributing to or inducing systemic change.
Building on these conceptual premises, it becomes obvious that when a researcher develops a system concept appropriate to guide a research, compiling (1) boundary judgements, (2) hierarchies of systems and subsystems, (3) different elements and their relationships, (4) purposes and (5) performance criteria, this is a system composition, which represents 'the person and their system of interest' (Ison 2012, p. 151). Essentially, such systems practice requires an open and curious attitude of the researcher towards the implications and consequences of one's own study interests, epistemological awareness and flexibility in using concepts (Fig. 4.7).

\subsection{Inter- and Transdisciplinary Research Practice}

When outlining the principal characteristics of inter- and transdisciplinary research practice in bioeconomy, we emphasise commonalities more than differences of the two approaches. These common components thus comprise the integrative design of the research, the team collaboration of the involved actors, the joint conception of the research problem and the necessity of integrating and synthetising knowledge from various disciplines and sources (Jahn et al. 
2012; Zscheischler and Rogga 2015). The distinction mainly consists in the professional orientation of the involved actors: in the case of interdisciplinarity, all actors have a professional background in academia, and scientific interests dominate, whereas in the case of transdisciplinarity, stakeholders and actor groups also partake, and a range of diverse outcomes are expected, including those of practical value for real-life questions (cf. Sect. 4.1). Differences in interests and impacts resulting for the researchers in particular are addressed in Sect. 4.5. Here, we present essential principals and steps of transdisciplinary research practice as structured by Lang et al. (2012) in three main phases (Fig. 4.8):

- The problem framing and team building phase

- The co-creation of solution-oriented transferable knowledge phase
- The (re)integration and application of created knowledge phase

\subsubsection{The Problem Framing and Team Building Phase}

By its very definition, inter- and transdisciplinary research starts with the perception of a (somehow) complex real-life problem (Sect. 4.1.2). We propose as example the bioeconomy-related question whether and under what conditions agriculture provides raw materials for the construction sector. The framing of such a problem and the composition of a team that engages in interor transdisciplinary research on this behalf is mutually interwoven: so, a perceived problem may constitute the starting point for the composition of a team which then will together specify and define this problem with more details. For

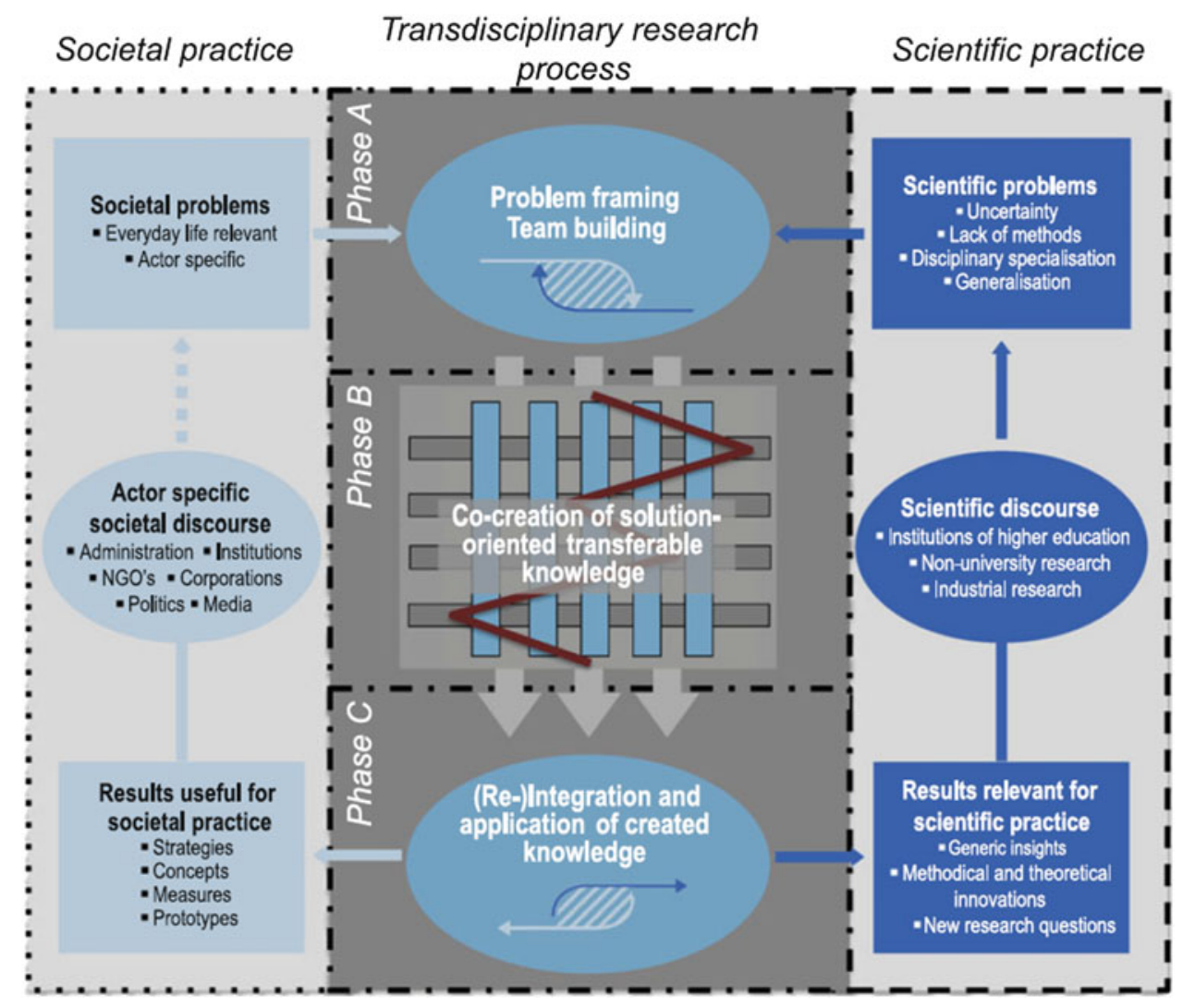

Fig. 4.8 Conceptual model of an ideal-typical transdisciplinary research process (Lang et al. 2012, p. 28) 
example, if the perceived challenge is located in the agricultural production sphere predominantly, then agronomists and farm economists might be the first ones to be involved but also farmers. If in contrast, the perceived challenge is located in the technological procedure of integrating new materials into known construction processes, construction engineers and material processing experts might be involved at first hand. Next question then could be how the market would react, so that marketing experts and potential consumers would be required. From these short considerations, it becomes evident that a range of actors has to be included in order to obtain a more complete understanding of a problem situation. And consequently, an interdependency is revealed between the actors describing the research problem and the way it is perceived and embedded into cause-effect relations and the expected results and outcomes of the study. Summarising, the very first challenge of inter- and transdisciplinary research is to frame a problem appropriately and to unite a group of scientists (and other actors) whose composition is sufficiently broad and deep in its expertise to generate meaningful answers. In transdisciplinary studies, such a straight problem orientation has proven an effective instrument for successful identification and mobilisation of stakeholders (Knierim 2014).

So, once the problem is - at least initiallyencircled and a number of concerned actors identified, the second and consecutive challenge of the first research phase is to set up the team's collaboration and to concretely implement the cooperation. In other words, how to practise a working procedure that allows both individual and group performances, so that the expertise of all actors involved can unfold? What exactly will be studied and how? What will be the responsibilities and tasks of the various actors? How will the results be determined? Clearly, these skills cannot be learned through books or taught in lectures but require a reflexive learning-bydoing approach. One basis for such skills can be a targeted team work training where steps of an action-oriented research process are practised separately and evaluated in mixed teams' settings. This is the case of the $\mathrm{UHOH}$ bioeconomy master. Another option for a learning context is to introduce the problemand project-based learning approach (Barrett 2005; Savery 2006) as a key feature.

Specific to transdisciplinary research is the integration of actors other than scientists. A widely used term for these actors is 'stakeholders'. Stakeholders are persons, groups or collective actors with interests in and/or influence on the addressed issue (see also Sect. 4.2.3). According to this definition, a fundamental stakeholder classification proposes groups according to (1) problem ownership, (2) actors who have interest in outcomes and (3) the actors' ability to act and to influence and shape project outcomes. Thus, stakeholder identification in transdisciplinary research necessitates both an understanding of the research question, so that boundaries of the social and ecological system can be established, and an overview of required resources, rights and capabilities that are necessary to successfully complete the project. It is an iterative process, where stakeholders might be added as the analysis continues. In practice, it is often not possible to identify all concerned stakeholders, and it is necessary to draw a line at some point, based on predetermined and welldefined decision criteria, to stop the selection and recruitment process (Gerster-Bentaya 2015; Grimble and Wellard 1997).

In order to appropriately address practitioners and to understand and assess roles, agencies and power constellations of actors involved, a stakeholder analysis is an essential step (GersterBentaya 2015). With regard to the categorisation of stakeholders, the first question to be addressed is: Who classifies them? In the case of top-down 'analytical categorisations', stakeholders are classified by researchers or experts, while bottom-up 'reconstructive methods' allow the categorisations and parameters in a stakeholder analysis to be defined by the stakeholders themselves. General stakeholder classification criteria may be based on interest and influence, legitimacy and resources and networks or types of 
activities. The influence-interest (II) matrix is commonly used to categorise stakeholders according to their interest and influence (Fig. 4.9).

Although this II matrix is very intuitive, many analyses fail to identify important stakeholders due to an insufficient clarification of 'interests' and sources of 'influence'. The level of interests is mainly about achieving benefits, but it is also about avoiding burdens. In the constructed case of agricultural raw materials for the construction sector, competing producers, e.g. from forestry would be considered as stakeholders too. Benefit and burden sharing is central to any type of projects. However, benefits and burdens may be direct and immediate or indirect and long term. Also, not all impacts are material. Cultural impacts are usually symbolic and immaterial

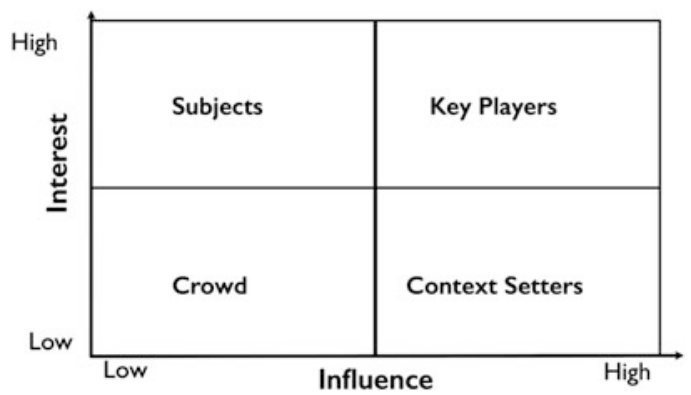

Fig. 4.9 System for classifying stakeholders according to interest and influence (Grimble and Wellard 1997, p. 176) (e.g. social recognition). Also, interest does not necessarily imply active involvement. Sometimes, actors are not aware of possible costs and benefits or incapable of acting and thus appear to be 'passive' (Nagel 2001). Actors may be able to influence the outcome of a project even if they do not have an interest in project outcomes.

Influence can be based on multiple sources of power. Legitimacy (of defining rules) is an important source of power. It is often linked to an institutional position with ascribed or acquired rights, e.g. which are formalised by law such as public sector organisations or landowners. Sometimes legitimacy may derive from the task being undertaken or through public consent or from bodies which are considered to be legitimate (e.g. scientific organisations, 'moral' institutions). Resources are knowledge, expertise and capabilities, as well as material resources that allow the key stakeholder to exert a formative influence on the issue and the research objective or to manage and monitor access to these resources (e.g. experts, funding institutions, media). Finally, influence may derive from social connections and the number and quality of relationships to other actors who are under obligation to or dependent on the stakeholder. In Table 4.5, a selection of stakeholders is presented to exemplify the categories 'context setters', 'subjects' and 'key players'.

Table 4.5 Examples of stakeholder types (compilation of the authors)

\begin{tabular}{ll} 
Context & Funding organisations \\
setters & $\begin{array}{l}\text { Relevant public administration that is not directly involved in the project } \\
\text { Political parties/organisations } \\
\text { Representative organisations from relevant sectors (national/international) } \\
\text { Research community } \\
\text { Governmental agencies }\end{array}$ \\
Subjects & $\begin{array}{l}\text { Public/target groups } \\
\text { Private sector organisations and individuals who have a current or potential future vested interest in } \\
\text { an area } \\
\text { Neighbourhood } \\
\text { Contractors }\end{array}$ \\
\hline Key players & $\begin{array}{l}\text { Local municipalities/regional administrations } \\
\text { Landowner/local businesses that may implement solutions } \\
\text { NGOs representing target groups } \\
\text { Project team/employees }\end{array}$ \\
\hline
\end{tabular}




\subsubsection{The Co-creation of Solution- Oriented Transferable Knowledge}

Thomas Jahn (2008) has highlighted four integration dimensions of the transdisciplinary research process. The cognitive-epistemic (or knowledge) dimension is the connection and amalgamation of discipline-specific as well as scientific and non-scientific knowledge. The social and organisational dimension means identification and acknowledgement of interests and activities of project partners. Stakeholder analysis is the core tool of this dimension (cf. Sect. 4.4.1). The communicative dimension refers to the heterogeneous communication practices and community-specific terminologies. Participatory measures are central to this dimension. Finally, factual and technical dimension means the integration of partial solutions into a common socially and normatively embedded joint framework.

In the following, we will primarily focus on the communicative dimension, while aspects of the cognitive-epistemic and the factual and technical dimension will be dealt with in the final section.

Integration through communication requires a stakeholder management strategy and plan with a focus on communicative interactions, participation and involvement procedures that also includes an ongoing 'stakeholder monitoring'. Such a strategy may be built on differentiated forms of involvement of different actors or groups of actors. Stakeholder roles may be classified according to the ways their knowledge is included into the research process or, in other words, along the degree of participation realised (Knierim et al. 2010; Pretty 1995). In the most basic forms of interaction between researchers and other actors, stakeholders may be treated as learners and as (rather passive) recipients of information or knowledge adaptors. Even though transdisciplinary research does not simply intend to transfer knowledge, the group of stakeholders, which are not actively included in the research process, can be quite large. Stakeholders may also be a source of information. Most commonly through interviews and surveys, but also via focus groups or internet forums the viewpoints and experiences of stakeholders, who are otherwise not directly involved, may be collected, and made accessible to the research project. Similarly, stakeholders may be understood as experts of their own lives, livelihoods and experiences and thus have a consulting role. However, more in line with an equal-partner understanding of actors is the involvement of stakeholders as research collaborators in transdisciplinary studies. For instance, they may be included as practice partners, which provide access to their own life world, experiences and knowledge about how to deal with addressed challenges. Even further, stakeholders may be part of the research process contributing to the research by collecting data specifically for the purpose of the research. While research collaboration in its basic forms

Table 4.6 A typology of participation levels in research projects (modified following Pretty 1995, p. 1252)

\begin{tabular}{|l|l|}
\hline $\begin{array}{l}\text { Type of participation } \\
\text { Manipulative participation }\end{array}$ & $\begin{array}{l}\text { Characteristics of type } \\
\text { Actors inclusion is a pretext, they have no functional role }\end{array}$ \\
\hline $\begin{array}{l}\text { Passive participation } \\
\text { Participation by } \\
\text { consultation }\end{array}$ & $\begin{array}{l}\text { Actors are considered as 'learners', they receive information } \\
\text { perceptions, opinions, etc. They have no part in decision making on the project's issues }\end{array}$ \\
\hline $\begin{array}{l}\text { Participation for material } \\
\text { incentives }\end{array}$ & $\begin{array}{l}\text { Actors contribute to research with information and/or labour etc. and receive in turn } \\
\text { material advantages and resources }\end{array}$ \\
\hline Functional participation & $\begin{array}{l}\text { Actors are involved as their competences, resources and/or societal positions are } \\
\text { relevant to the aim of the project. They may have an influence in the research design and } \\
\text { decision-making processes related to the project's implementation }\end{array}$ \\
\hline Interactive participation & $\begin{array}{l}\text { Actors participate as equal partners throughout the research phases, participate in } \\
\text { decision-making and share responsibilities and resources }\end{array}$ \\
\hline
\end{tabular}


only treats stakeholders as helpers, they may also be involved as creative actors who actively contribute to the development of the research design and interpretations. Irrespective of other types of involvements, a main role of stakeholders in transdisciplinary research projects is that of validators of research findings (cf. Table 4.6).

Most obviously, the practical ways how actors are involved in the joint research and development process of a transdisciplinary study are determinative for the participation realised. Here, Pohl and Hirsch Hadorn (2008a) differentiate between 'forms of transdisciplinary collaboration' and 'means of integration' based on their experiences as transdisciplinary researchers. The three ways to implement transdisciplinary cooperation are common group learning, deliberation among experts, and integration by a subgroup or individual. While in the first case cooperation happens as a whole group learning process, in the second case, team members with relevant expertise on the components of the problem join their views in form of a deliberative process. In the third case, the act of integration happens through the work of a specific subgroup or an individual who work(s) on the behalf of all (Pohl and Hirsch Hadorn 2008a, p. 115). As 'means of integration', the authors propose four 'classes of tools': mutual understanding, theoretical concepts, models and products (ibid). Obviously, the question of mutual understanding is one of having a common language, of seeking to avoid too specific, disciplinary terms and of spending time for explanation and listening. Secondly, 'challenges in integration are about creating or restructuring the meaning of theoretical and conceptual terms to capture what is regarded as relevant in problem identification and framing. Therefore, a second group of integration "tools" comprises theoretical notions [theoretical concepts], which can be developed by (1) transferring concepts between fields, (2) mutually adapting disciplinary concepts and their operationalisation to relate them to each other, or (3) creating new joint bridge concepts that merge disciplinary perspectives' (ibid, p. 116). As third means of integration, Pohl and Hirsch Hadorn (2008a) propose models-ranging on a continuum from purely quantitative (mathematical) to purely qualitative (descriptive) and they emphasise that '(semi-)qualitative system dynamics models are often developed in a collaborative learning process among researchers and other stakeholders, aiming at a shared understanding of the system, its elements and their interactions'. In this regard, we refer to the use of a conceptual frame as presented in the Sect. 4.3.4. Finally, as a fourth means, products are designated, which can be of any kind such as marketable products, knowledgesharing devices or even institutions, etc.

\subsection{3 (Re)integration and Application of Created Knowledge}

Interdisciplinary integration raises the issues of the compatibility and connectivity of disciplinespecific knowledge. Integration in this sense has to be seen in both directions. On the one hand, a joint definition of 'study objects' and scientific models is required, which goes beyond disciplinary perspectives. On the other hand, the new knowledge has also to be transferred back into disciplinary discourses. Similarly, the integration of research results comprises, in one respect, summarising and validation of case specific knowledge with regard to problem under investigation. The evaluative focus from such a perspective is on usability. In another vein, scientists have to, at least partly, retransfer the new knowledge in discipline-specific context. This requires the identification of generalisable, nomothetic parts of knowledge (Lang et al. 2012).

Research outcomes of transdisciplinary research (concepts, methods and products) are evaluated from two different perspectives. Firstly, outcomes are assessed with regard to their usability, their practical relevance. Local actors care for their case and not for any general knowledge. To solve the problem 'in principle' would not be acceptable to the audience and the local actors who push the case. Thus, each case has its individual value, because the involved 
actors are engaged in solving their specific issue, not a general problem! Secondly, scientists search for the more general features of a case and the advancement of scientific knowledge in general. The evaluative question here is 'are the cases telling us that some nomothetic lessons can be learned despite their situational conditions, or that lessons can be learned because they are embedded in real world contexts?'

As it has been outlined in the earlier sections, the origins of the concept of transdisciplinarity lie in a perceived mismatch between types of knowledge produced in the field of sciences and the demand for problem-solving solutions of society. This mismatch can partly be traced back to the type of (generalised) knowledge generated through sciences and the neglect of actors' practical, often tacit and context-specific, knowledge. Also, science has increasingly specialised in an escalating number of disciplines. While this specialisation has allowed to catalyse scientific knowledge growth, it has increasingly become a hindrance for the solution of 'real'-world problems, which usually combine multiple dimensions in a complex manner. Therefore, solutions require the integration of different perspectives.

In practice, it is argued that for solving 'real'world problems, three different types of knowledge are needed. They go across scientific disciplines as well as beyond purely scientific knowledge: system, target and transformation knowledge. Systems knowledge can be seen as an understanding of the nature of a problem, the causalities and conditioning context. In the example of bio-based construction materials, knowledge about the production and the processing of these materials would fall in the 'systems knowledge' category. Scientific knowledge is particular important for the analysis of problems, while the definition of the problem may derive from science but also from the societal context (lifeworld) itself. However, local actors may also hold and contribute substantial practical knowledge about many aspects of the functioning of the investigated system, e.g. do farmers have practical knowledge about how to produce best on their land and under the given natural and climatic restrictions. Target knowledge is defined as an understanding of actors, their interests, concerns and capacities, and it is developed on the basis of values and norms that guide decision-making. Social research may be used to describe the social sphere, but, again, the actors themselves share a detailed knowledge about its nature. So, the question whether and to what share fossil energy or renewable material-based resources shall be used in construction is one that is solved based on target knowledge. Finally, transformative knowledge provides answers about changing practices and institutions. While the first two types of knowledge are describing the status quo, and may help to define a desired future state, the transformative knowledge is crucial in order to describe a path, the operational steps from the current to a desired state (cf. Fig. 4.1). While the systems and target knowledge form a necessary prerequisite and - at least in principal — can be undertaken in purely disciplinary scientific research manner, transformative knowledge can be understood as the essence of transdisciplinary research, in which multiple forms of scientific/ practical and multidisciplinary perspectives are combined and transformed.

\subsection{Researchers' Norms, Values and Agency in Inter- and Transdisciplinary Bioeconomy Research}

In Sect. 4.1, the important role of inter- and transdisciplinary research for Western societies' bioeconomy strategies was outlined. In other words, interactive knowledge creation and innovation development are core concepts related to bioeconomy politics and programs. Thus, scientists' roles and tasks for the advancement and implementation of bioeconomy may not be underestimated but, on the contrary, need to be explicitly addressed and taken seriously in all consequences. As was argued in Sects. 4.3 and 4.4 , the conceptual backgrounds of interand transdisciplinary research and its design and implementation are predominantly authored by members of the academic communities. So, 
what are the norms and values and how do scientists' roles and tasks impact and influence the process and the results of inter- and transdisciplinary research?

In the following, these questions will be discussed referring to two key characteristics of inter- and transdisciplinary research: (1) the way how participation is put into practice and (2) the design and agreement of the conceptual framework.

\subsubsection{Researchers Norms, Values and Practices with Regard to Participation}

There is empirical evidence that besides classical scientific procedures, researchers in inter- and even more in transdisciplinary research settings frequently adopt multiple roles, such as 'facilitation of the working process', 'mediating among heterogeneous interests', 'consulting practitioners about possible solutions', 'communicating results to decision makers', etc. Whether or not these roles and functions are consciously adopted or ascribed by the environment, they imply that researchers give up their classical distant observatory and reflective attitude and become active in communication and interaction (Knierim et al. 2013). Hereby, values and norms about how effective communication and decision-making take place become relevant and impact on the individual behaviour in communication and interaction settings. For example, Schmid et al. (2016) have shown that scientists with a positive attitude towards transdisciplinary research conducted more interactive events with practitioners than their colleagues who were more sceptical towards transdisciplinary research. One key determinant in this regard is the question whether or not researchers affirm the necessity of and practice an 'open process' attitude in cooperation with other actors. Considering participation as an 'open' or 'emerging process' (Greenwood et al. 1993, p. 179) means that when a research process starts, it is not predetermined to which degree the interactive cooperation among the actors will be realised but that it evolves in the course of the work.
Besides, the same authors argue it is the (social science) researchers' capacity and responsibility to behave in a way that a maximum of participation can be reached in such collaboration processes. This requires a high degree of trust in one's own and others capacity to bear and to deal with uncertainty. A second necessary skill is reflexivity expressed as a continuous attention for the procedural part of the research. Here, the will to learn not only about contents from other disciplines but also about methods and procedures for adequate and effective communication and collaboration among various actors is a prerequisite.

\section{Reflexivity and Engagement}

A key quality of researchers with responsibility in a transdisciplinary research process is mental openness for perceiving a situation repeatedly anew and to act within this systemic context, on the basis of reflexivity (see Sect. 4.3.3). Engaging for an appropriate degree of participation of all other actors involved constitutes a second necessary ingredient for successful cooperation (see Table 4.6). Both practices require a positive attitude towards communication and interaction in social systems.

Given the fact that scientists are frequently the drivers of transdisciplinary research settings and processes, it is not surprising that they comeintended or unintendedly - in charge of designing and managing the collaboration process. Manifold questions have to be tackled in a transparent way, such as: Who defines the research agenda? Which interests are reflected in the research agenda and which interests are perhaps ignored? A further issue is the accountability of science. If science autonomously defines the research process and its quality criteria, is there any chance for the society to influence the research process and the nature of the outcomes?

Summarising, the expectations on researchers involved in inter- and transdisciplinary studies are uncontestably higher than those on classical researchers: they are more divers with regard to methodological skills and practices at hand, and 
they imply a certain readiness to reveal and reflect upon one's sociopolitical norms and values that guide actions with societal relevance (Knierim et al. 2013).

\subsubsection{Researchers' Roles in the Design and Implementation of Conceptual Ideas and Frameworks}

As argued in Sect. 4.4, the success of collaboration among various actors and actor groups throughout a transdisciplinary research process strongly depends on a common understanding of the nature of the problem studied and the appropriate concepts that guide the structuring of the problem and related solutions (cf. Chap. 11). Hence, there is a process of conceptualisation which is (at least) guided (if not determined) by the involved scientists: (1) it starts with the development of a general understanding of what 'bioeconomy' is (cf. Sect. 4.1.1) and how the studied problem relates to it, it continues with the judgement for which bioeconomy questions and challenges research resources should be allocated and it concretises even more in the conceptual framework concept that orients an inter- or transdisciplinary research. Throughout these steps, the researcher (s) strongly and more or less explicitly shapes the way bioeconomy research is understood and realised. Thus, researchers are important drivers in the process of the 'institutionalisation of bioeconomy' because they themselves contribute to the creation and stabilisation of institutions as:

- Developers of aims and objectives in bioeconomy-related research

- Knowledge and innovation creators related to bioeconomy

- Facilitators of stakeholders' participation in such research.

Institutions can be defined in various ways. In abstract words, they are 'prescriptions that humans use to organize all forms of repetitive and structured interactions' (Ostrom 2005, p. 3).
So, in general, certain social functions are assigned to institutions such as creating stability and reliability among people. The process of creating institutions (institutionalisation) in modern societies is often interpreted as a process of establishing and assigning new rationality criteria to specialised action arenas. In a sociological perspective, the transition to a bio-based economy requires the institutionalisation of, e.g. recycling or of a preference of biomass usage over fossil resources, etc.

\section{Box 4.7 Institutions}

A more general definition sees institutions as a set of stabilised social practices/ interactions. This may be an individual morning ritual (breakfast with coffee, cleaning the teeth), an institutionalised social group activity or interaction (e.g. having a joint family breakfast at 7 a.m.), collective structure (the family as a social institution) or even a wider organised social structure (e.g. the educational system).

In a narrow sense, institutions are often defined as the 'rules of the game', thus referring to the normative order of individual practices and social interactions. From this perspective, institutions reduce the social complexity and ease individual choices (routine) but also social interactions, since actors do not have to negotiate all aspects of action situations. The establishment of a normative order requires a process of socialisation, in which actors learn (internalisation) an established normative order. Thus, institutions are related to knowledge in the way that they require actors' knowledge to function, but also offer values, meaning and knowledge to actors about 'why' and 'how to act'. Institutions also require external control and sanctioning (rewards as well as punishment) mechanism (governance).

Through their engagement when developing conceptual frameworks for research in 
bioeconomy, scientists contribute to this institutionalisation process. For example, when conceiving the invention of 'new' products or production processes, scientists do implicitly or explicitly also cause the emergence of 'property rights' on the result. Three fundamental steps in this process are captured with the terms 'reification' and 'commodification'.

Reification is the process of making something 'real'. Bioeconomy is based on the creation of new 'objects' of interest for society (e.g. new bio-based materials out of existing 'waste', enzymes, DNA, etc.). A prominent example in this regard is DNA: The DNA was always there, but only its recognition and the development of technical tools for its manipulation have transformed DNAs into objects of interest for society. The processes of reification primarily triggered ethical debates: in how far are we morally authorised to transform nature objects, parts of bodies, etc. into parts/materials for human usage? Commodification means transformation of formerly non-traded objects into tradable commodities (e.g. blood, organs, waste). Commodification requires the assignment of property rights to new (property) objects. The concept of bioeconomy is based on an extensive process of commodification of objects (e.g. patenting of DNA code), which were formerly regarded as gifts (organs/blood) or waste (a non-property/'res nullius') and which are now transformed into valuables.

In most cases, the role of individual researchers with respect to the institutionalisation of bioeconomy is by far not that influential as the one $\mathrm{s} / \mathrm{he}$ has on the degree of interactive participation in the cooperation process. Here, it is the multitude of choices and decisions taken by a certain number of researchers engaged in bioeconomy which results in orientations of objectives, channelling of funds and finally institutionalisation of conceptualisations and research practices. Nevertheless, as there is obviously some definition power and impact on shared understandings on scientists' side, also this part has to be recognised, openly addressed and-where necessary negotiated-in inter- and transdisciplinary research projects.

Summarising, this section showed that researchers' impact on processes, outputs and outcomes of inter- and transdisciplinary research should not be underestimated. On the contrary, it is important to take the various roles, functions and tasks, which arise in the process of participatory cooperation, as serious as possible and to accept and perform or reject (and if necessary delegate) them openly (Knierim et al. 2013) in order to come to meaningful and reliable results that are relevant and appropriate to solving practical problems within the society.

\section{Review Questions}

- What is 'a problem'? Why is it important to understand the nature of 'wicked problems' in the context of bioeconomy?

- What is meant by multi-, inter- and transdisciplinary research? What are differences and similarities among these research approaches?

- How do you explain 'a system'? How is this concept used in social and in natural sciences? Why is a system concept a good basis for inter- and transdisciplinary research?

- What are characteristics of inter- or transdisciplinary research processes, which characteristic phases can be detected, which responsibilities result for scientists?

\section{References}

Agyris C (2005) Actionable knowledge. In: Knudsen C, Haridimos $\mathrm{T}$ (eds) The Oxford handbook of organisation theory. Oxford University Press, Oxford, pp 423-452

Barrett T (2005) Understanding problem-based learning. In: Barrett T, Mac Labhrainn I, Fallon H (eds) Handbook of enquiry \& problem based learning. AISHE and CELT, NUI Galway, Galway

Batie SS (2008) Wicked problems and applied economics. American Journal of Agricultural Economics. 90 (5):1176-1191. https://doi.org/10.1111/j.1467-8276. 2008.01202.x 
Bergmann M, Jahn T, Knobloch T et al (2010) Methoden transdisziplinärer Forschung: Ein Überblick mit Anwendungsbeispielen. Campus Verlag, Frankfurt am Main

Bloch R, Knierim A, Häring AM et al (2016) Increasing the adaptive capacity of organic farming systems in the face of climate change using action research methods. Org Agric 6(2):139-151

BMBF (Federal Ministry of Education and Research of Germany) (2010) National research strategy bioeconomy 2030. Our Route towards a biobased economy. https://www.bmbf.de/pub/National_ Research_Strategy_BioEconomy_2030.pdf. Accessed 15 Feb 2017

BMEL (Federal Ministry of Food and Agriculture of Germany) (2014) National policy strategy on bioeconomy. Renewable resources and biotechnological processes as a basis for food, industry and energy. Available from: http://www.bmel.de/SharedDocs/ Downloads/EN/Publications/NatPolicyStrategyBioe conomy.pdf?_blob=publicationFile. Accessed 25 Dec 2016

Bonaiuti M (2015) Bio-economics. In: D'Alisa G, Demaria F, Kallis G (eds) Degrowth: a vocabulary for a new era. Routledge/Taylor \& Francis Group, New York, pp 25-28

Brand KW (ed) (2000) Nachhaltige Entwicklung und Transdisziplinarität: Besonderheiten, Probleme und Erfordernisse der Nachhaltigkeitsforschung. Analytika-Verlag, Berlin

Castán Broto V, Gislason M, Ehlers MH (2009) Practising interdisciplinarity in the interplay between disciplines: experiences of established researchers. Environ Sci Policy 12(7):922-933. https://doi.org/10.1016/j. envsci.2009.04.005

Checkland PB (1999) Soft systems methodology: a 30 year retrospective. Wiley, Chichester

Checkland PB, Poulter J (2006) Learning for action. A Short definitive account of soft systems methodology and its use for practitioners, teachers and students. Wiley, Chichester

Darnhofer I, Gibbon D, Dedieu B (2012) Farming systems research: an approach to inquiry. In: Darnhofer I, Gibbon D, Dedieu B (eds) Farming systems into the 21st century: the new dynamic. Springer, Dordrecht, pp 3-31

European Commission (2012) Innovating for sustainable growth: a bioeconomy for Europe. DirectorateGeneral for Research and Innovation, the EU. http:// bookshop.europa.eu/en/innovating-for-sustainablegrowth-pbKI3212262/. Accessed 12 Jan 2016

Fischer-Kowalski M, Weisz H (1999) Society as hybrid between material and symbolic realms. Toward a theoretical framework of society-nature interaction. Adv Hum Ecol 8:215-251
Foucault M (1981) The order of discourse. In: Young RJC (ed) Untying the text: a post-structuralist reader. Routledge/Kegan \& Paul, Boston/London, pp 48-78

GAIA (2007) Schwerpunkt Transdisziplinarität. GAIA 16 (1):27-65

Geels FW (2002) Technological transitions as evolutionary reconfiguration processes: a multi-level perspective and a case-study. Res Policy 31:1257-1274

Geertz C (1973) Thick description: toward an interpretive theory of culture. In: The interpretation of cultures: selected essay. Basic Books, New York

Gerster-Bentaya M (2015) Stakeholder analysis. In: Giseke U, Gerster-Bentaya M, Helton F, Kraume M, Scherer D, Spars G, Amraoui F, Adidi A, Berdouz S, Chlaida M, Mansour M, Mdafai M, Helten F (eds) Urban agriculture for growing city regions. Connecting Urban-rural spheres in Casablanca. Routledge, Abingdon

Greenwood DJ, Foote White W, Harkavy I (1993) Participatory action research as a process and as a goal. Hum Relat 46(2):175-192

Grimble R, Wellard K (1997) Stakeholder methodologies in natural recourse management: a review of principles, contexts, experiences and opportunities. Agric Syst 55(2):173-193

Grunwald A, Schmidt JC (2005) Method(olog)ische Fragen der Inter- und Transdisziplinarität. Wege zu einer praxisstützenden Interdisziplinaritätsforschung. Technikfolgenabschätzung - Theorie und Praxis 2 (14):4-16

Hajer MA (1995) The politics of environmental discourse: ecological modernization and the policy process. Clarendon Press, Oxford

Hirsch Hadorn G, Hoffman-Riem H, Biber-Klemm S et al (2008) Handbook of transdisciplinary research. Springer, London

Hoffmann V (2007) Book review on Rogers, E.M. Diffusion of innovations. J Agric Educ Ext 13 (2):147-158

Hoffmann V, Gerster-Bentaya M, Christinck A et al (2009) Handbook: rural extension, Basic issues and concepts, vol 1. Margraf Publishers $\mathrm{GmbH}$, Weikersheim

Huber J (2011) Allgemeine Umweltsoziologie, 2nd completely revised edition. VS Verlag für Sozialwissenschaften, Wiesbaden

Ison R (2010) Systems practice: how to act in a climatechange world. Springer, London

Ison R (2012) Systems practice: making the systems in farming systems research effective. In: Darnhofer I, Gibbon D, Dedieu B (eds) Farming systems into the 21st century: the new dynamic. Springer, Dordrecht, pp 141-157

Jahn T (2008) Transdisziplinarität in der Forschungspraxis. In: Transdisziplinäre Forschung. 
Integrative Forschungsprozesse verstehen und bewerten. Campus Verlag, Frankfurt/New York, pp 21-37

Jahn T, Bergmann M, Keil F (2012) Transdisciplinarity: between mainstreaming and marginalization. Ecol Econ 79:1-10

Janssen K (2009) Implicit sociology, interdisciplinarity and systems theories in agricultural science. Sociol Rural 49(2):172-188. https://doi.org/10.1111/j.14679523.2009.00486x

Knierim A (2014) Stakeholder involvement for developing adaption innovations in rural areas: examples from Berlin-Brandenburg. In: Prutsch A, McCallum S, Swart RJ (eds) Climate change adaptation manual: lessons learned from European and other industrialised countries. Routledge, Oxfordshire, pp 128-135

Knierim A, Pintar M, Skerratt S et al (2010) The InnoLand approach: experimental research and action in Europe's rural regions. In: Wiggering H, Ende HP, Knierim A, Pintar M (eds) Innovations in European rural landscapes. Springer, Berlin, pp 11-24

Knierim A, Baasch S, Gottschick M (eds) (2013) Partizipation und Klimawandel: Ansprüche, Konzepte und Umsetzung. Oekom, Munich

Knorr-Cetina K (1981) The manufacture of knowledge: an essay on the constructivist and contextual nature of science. Pergamon Press, Oxford

Kuhn TS (2012) The structure of scientific revolutions. 50th Anniversary Edition, 4th edition. University of Chicago Press, Chicago

Lang JD, Wiek A, Bergmann M et al (2012) Transdisciplinary research in sustainability science: practice, principles, and challenges. Sustainable Science 7 (1):25-43

Lockaby BG, Zhang D, McDaniel J et al (2005) Interdisciplinary research at the urban-rural interface: the WestGa project. Urban Ecosyst 8(1):7-21

Long N, Long A (1992) Battlefields of knowledge: the interlocking of theory and practice in social research and development. Routledge, London

Luhmann N (2013) Introduction to systems theory. Polity Press, Cambridge

Messerli B, Messerli P (2008) From local projects in the Alps to global change programmes in The mountains of the world: Milestones in transdisciplinary research. In: Hirsch Hadorn G, Hoffman-Riem H, BiberKlemm S, Grossenbacher-Mansuy W, Joye D, Pohl C, Wiesmann U, Zemp E (eds) Handbook of transdisciplinary research. Springer, London, pp 43-62

Mittelstraß J (1987) Die Stunde der Interdisziplinarität. In: Kocka J (ed) Interdisziplinarität: Praxis Herausforderung - Ideologie. Suhrkamp, Frankfurt am Main
Müller K, Toussaint V, Bork HR et al (2002) Nachhaltigkeit und Landschaftsnutzung. Neue Wege kooperativen Handelns, Margraf Verlag, Weikersheim

Nagel UJ (2001) Actor involvement in extension - who actually decides what? In: Hoffmann V (ed) 50 Years of Hohenheim extension studies. Margraf Verlag, Weikersheim, pp 59-65

OECD (Organisation for Economic Co-operation and Development) (1996) The knowledge-based economy. General distribution OECD/GD (96)102, Paris. Available from: https://www.oecd.org/sti/sci-tech/ 1913021.pdf. Accessed 25 Dec 2016

OECD (Organization for Economic Co-operation and Development) (2009) The bioeconomy to 2030. Designing a policy agenda. http://biotech2030.ru/ wpcontent/uploads/docs/int/The\%20Bioeconomy\% 20to\%202030_OECD.pdf. Accessed 15 Feb 2017

Ostrom E (2005) Understanding institutional diversity. Princeton University Press, Princeton

Ostrom E (2007) A diagnostic approach for going beyond panaceas. Special feature in going beyond panaceas. Proc Natl Acad Sci 104(39):15181-15187

Parsons T (1991) The social system. With a new preface by Bryan S. Turner. Routledge, London

Podestá GP, Natenzon CE, Hidalgo C et al (2013) Interdisciplinary production of knowledge with participation of stakeholders: a case study of a collaborative project on climate variability, human decisions and agricultural ecosystems in the Argentine Pampas. Environ Sci Policy 26:40-48. https://doi.org/10. 1016/j.envsci.2012.07.008

Pohl C, Hirsch-Hadorn G (2008a) Methodological challenges of transdisciplinary research. Nat Sci Soc 16:111-121

Pohl C, Hirsch-Hadorn G (2008b) Gestaltung transdisziplinärer Forschung. Sozialwissenschaften und Berufspraxis 31(1):5-22

Pretty JN (1995) Participatory learning for sustainable agriculture. World Dev 23(8):1247-1263

Rosenfield PL (1992) The potential of transdisciplinary research for sustaining and extending linkages between health and social sciences. Soc Sci Med 35:1343-1357

Savery JR (2006) Overview of problem-based learning: definitions and distinctions. Interdiscip J Probl Based Learn 1(1). https://doi.org/10.7771/1541-5015.1002

Schiere JB, Groenland R, Vlug A et al (2004) System thinking in agriculture: an overview. In: Rickert K (ed) Emerging challenges for farming systems - lessons from Australian and Dutch agriculture. Rural Industries Research and Development Corporation, Barton

Schmid JC, Knierim A, Knuth U (2016) Policyinduced innovations networks on climate change adaptation - an ex-post analysis of collaboration 
success and its influencing factors. Environ Sci Policy 56:67-79

Staffas L, Gustavsson M, McCormick K (2013) Strategies and policies for the bioeconomy and bio-based economy: an analysis of official national approaches. Sustainability 5:2751-2769

TA (Technikfolgenabschätzung - Theorie und Praxis) (2005) Schwerpunktthema-Method(olog)ische Fragen der Inter- und Transdisziplinarität - Wege zu einer praxisstützenden Interdisziplinaritätsforschung 2(14)

Tress G, Tress B, Fry G (2007) Analysis of the barriers to integration in landscape research projects. Land Use
Policy 24(2):374-385. https://doi.org/10.1016/j. landusepol.2006.05.001

White House (2012) National bioeconomy blueprint. The USA, Washington. http://www.eesi.org/files/national_ bioeconomy_blueprint_april_2012.pdf. Accessed 29 Jan 2017

Zhang D, Shen J (2015) Disciplinary foundations for solving interdisciplinary scientific problems. Int J Sci Educ 37(15):2555-2576

Zscheischler J, Rogga S (2015) Transdisciplinarity in land use science - a review of concepts, empirical findings and current practices. Futures 65:28-44

Open Access This chapter is licensed under the terms of the Creative Commons Attribution 4.0 International License (http://creativecommons.org/licenses/by/4.0/), which permits use, sharing, adaptation, distribution and reproduction in any medium or format, as long as you give appropriate credit to the original author(s) and the source, provide a link to the Creative Commons license and indicate if changes were made.

The images or other third party material in this chapter are included in the chapter's Creative Commons license, unless indicated otherwise in a credit line to the material. If material is not included in the chapter's Creative Commons license and your intended use is not permitted by statutory regulation or exceeds the permitted use, you will need to obtain permission directly from the copyright holder. 